\title{
əInterannual and Decadal Variability of Arctic Summer Sea Ice Associated with Atmospheric Teleconnection Patterns during 1850-2017
}

\author{
QiongQiong CAI, ${ }^{\mathrm{a}, \mathrm{b}}$ DMitry Beletsky, ${ }^{\mathrm{b}}$ Ja WANG,${ }^{\mathrm{c}}$ AND Ruibo Lei ${ }^{\mathrm{d}}$ \\ a National Marine Environmental Forecasting Center, Ministry of Natural Resources, Beijing, China \\ ${ }^{\mathrm{b}}$ Cooperative Institute for Great Lakes Research, School for Environment and Sustainability, \\ University of Michigan, Ann Arbor, Michigan \\ ${ }^{\mathrm{c}}$ NOAA Great Lakes Environmental Research Laboratory, Ann Arbor, Michigan \\ ${ }^{\mathrm{d}}$ Ministry of Natural Resources Key Laboratory for Polar Science, Polar Research \\ Institute of China, Shanghai, China
}

(Manuscript received 11 May 2020, in final form 10 September 2021)

\begin{abstract}
The interannual and decadal variability of summer Arctic sea ice is analyzed, using the longest reconstruction (1850-2017) of Arctic sea ice extent available, and its relationship with the dominant internal variabilities of the climate system is further investigated quantitatively. The leading empirical orthogonal function (EOF) mode of summer Arctic sea ice variability captures an in-phase fluctuation over the Arctic Basin. The second mode characterizes a sea ice dipolar pattern with out-of-phase variability between the Pacific Arctic and the Atlantic Arctic. Summer sea ice variability is impacted by the major internal climate patterns: the Atlantic multidecadal oscillation (AMO), North Atlantic Oscillation (NAO), Arctic Oscillation (AO), Pacific decadal oscillation (PDO), and the Dipole Anomaly (DA), with descending order of importance based on the multiple regression analyses. The internal climate variability of the five teleconnection patterns accounts for up to $46 \%$ of the total variance in sea ice mode 1 (thermodynamical effect), and up to $30 \%$ of the total variance in mode 2 (dynamical effect). Furthermore, the variability of sea ice mode 1 decreased from $46 \%$ during 1953-2017 to $28 \%$ during $1979-2017$, while the variability of mode 2 increased from $11 \%$ during 1953-2017 to 30\% during 1979-2017. The increasingly greater reduction of Arctic summer sea ice during the recent four decades was enhanced with the positive ice/ocean albedo feedback loop being accelerated by the Arctic amplification, contributed in part by the atmospheric thermodynamical forcing from $-\mathrm{AO},+\mathrm{NAO},+\mathrm{DA},+\mathrm{AMO}$, and -PDO and by the dynamical transpolar sea ice advection and outflow driven by +DA- and + AMO-derived strong anomalous meridional winds. Further analysis, using multiple large ensembles of climate simulations and single-forcing ensembles, indicates that mode 1 of summer sea ice, dominated by the multidecadal oscillation, is partially a forced response to anthropogenic warming.
\end{abstract}

KEYWORDS: Arctic; Sea ice; Arctic Oscillation; Atmosphere-ocean interaction; Teleconnections; Feedback

\section{Introduction}

Arctic sea ice variability has long been recognized as an important component of the climate system in the Arctic and on a global scale (Stroeve et al. 2007; Serreze and Barry 2011; Schweiger et al. 2019). It may modulate freshwater flux from the Arctic Ocean, deep water formation in the northern region of the Atlantic Ocean, and the intensity of large-scale ocean overturning (Aagaard and Carmack 1994). Sea ice has important local influences on the atmospheric energy budget through latent heat release and absorption of solar radiation during freezing and the melting of sea ice, respectively, so as to adjust the seasonality of the Arctic climate (Walsh 1983). It also affects the exchange of heat, moisture, and momentum between the atmosphere and ocean (Randall et al. 1998; Holland et al. 2001), and further modifies ice-ocean-atmosphere interaction by altering surface albedo (Lei et al. 2016).Using models with

¿ Denotes content that is immediately available upon publication as open access.

Corresponding author: Jia Wang, jia.wang@noaa.gov different configurations and projected sea ice losses, it is found the effects of Arctic sea ice loss are not limited to the northern high latitudes, but reach deep into the tropics: the entire troposphere warms, the global hydrological cycle strengthens, the intertropical convergence zones shift equatorward, and a reduction in strength and southward shift of the midlatitude westerly winds in winter occur (Deser et al. 2015; Screen et al. 2018; England et al. 2020).

The pronounced decline in summer Arctic sea ice cover that began in the late twentieth century is unprecedented in both magnitude and duration for at least the past 1450 years, with large interdecadal and interannual variability (Kinnard et al. 2011). In recent decades, acceleration of ice decline is also evident as trends in yearly extent have increased from about $-0.23 \times 10^{6} \mathrm{~km}^{2}$ decade $^{-1}$ in $1979-86$ to $-0.55 \times$ $10^{6} \mathrm{~km}^{2}$ decade ${ }^{-1}$ over the period 1979-2017 (Parkinson and Cavalieri 1989; Brennan et al. 2020). The seasonal daily minimum extent hit a record low in 2012, and September 2020 was the second lowest extent in the satellite record (Parkinson and Comiso 2013; Meier et al. 2020).

Previous studies suggest that there are certain teleconnections and feedbacks between the Arctic sea ice and the internal variabilities of the climate system on the interannual to decadal 
time scales (Walsh and Johnson 1979; Levitus et al. 2009; Serreze and Stroeve 2015). Ding et al. (2017, 2019) indicated that the internal variability dominates the Arctic summer circulation trend and may be responsible for about $30 \%-50 \%$ of the observed multidecadal decline in Arctic sea ice. The Arctic Oscillation (AO) and North Atlantic Oscillation (NAO) associated with the subsidence-induced adiabatic warming and moistening anomalies in the lower troposphere may enhance sea ice loss (Sedlar and Tjernström 2017; Hegerl et al. 2018; Olonscheck et al. 2019; Ding et al. 2019; Serreze et al. 2019; Papritz 2020). Dynamically, the more anomalous cyclonic (anticyclonic) atmospheric and ocean circulation also favors increased (reduced) sea ice due to sea ice divergence (convergence) and southward (northward) Ekman drift of sea ice in marginal ice zone (Wang and Ikeda 2000, 2001; Ogi and Wallace 2007; Peralta-Ferriz and Woodgate 2017; Olonscheck et al. 2019; Ding et al. 2019; Serreze et al. 2019; Yu et al. 2019). The Arctic Dipole Anomaly (DA), consistent with a tendency toward warm air advection into the European Arctic and hence Arctic warming, also induces an enhanced transpolar wind/ice drift due to its strong meridional forcing (Overland and Wang 2005; Wu et al. 2006; Watanabe et al. 2006; Wang et al. 2009; Ikeda 2012; Zhang 2015; Lei et al. 2016; Hegerl et al. 2018).

The Atlantic multidecadal oscillation (AMO) can drive lowfrequency Arctic sea ice fluctuations by triggering anomalous atmospheric circulation and anomalous warm or cold air advection into the Arctic Ocean (Castruccio et al. 2019; Yu et al. 2019). About $5 \%-31 \%$ of the $10.1 \%$ decade $^{-1}$ decline in September sea ice extent (1979-2010) is attributed to AMOdriven variability (Day et al. 2012). The Pacific decadal oscillation (PDO) appears to play a key role in the accelerated Arctic warming (Svendsen et al. 2018; Tokinaga et al. 2017; Hegerl et al. 2018; McCrystall et al. 2020) and has led to faster winter sea ice loss with increased poleward energy transport in recent decades (Meehl et al. 2018; Screen and Deser 2019; Yu et al. 2019).

Cai et al. (2021) evaluated the trends of summer sea ice in six Arctic regions and showed that the key drivers to the accelerated summer sea ice decline during the last several decades are found to be the combined global warming and regional Arctic warming exerted simultaneously by the internal variability of the teleconnection patterns (AO, NAO, AMO, PDO). Built upon on Cai et al.'s recent findings, this research is devoted to assessing interannual and decadal variability of summer Arctic sea ice using empirical orthogonal function (EOF) analysis. The contributions of atmospheric dynamical and thermodynamical forcing induced by the AO, NAO, DA, AMO, and PDO are further investigated and compared quantitatively. We will address the following questions: 1) What are the thermodynamical impacts of the individual teleconnection patterns on changes in Arctic surface temperature structure and sea ice distribution? 2) What are the dynamical forcings of these teleconnections that drive Arctic sea ice advection? 3) What is the quantitative relevance of each teleconnection causing observed sea ice variability? 4) How do the atmospheric thermodynamical forcing and wind forcing by the dominant modes of climate variability, combined with the global warming, accelerate the decline in Arctic summer sea ice in recent decades?
Section 2 describes the data and methods used in this study. Section 3 explores the Arctic sea ice interannual and decadal variability and its association with dominant internal variabilities of climate system. Section 4 summarizes the findings of this study.

\section{Data and methods}

\section{a. Data}

\section{1) SEA ICE}

We used the gridded monthly sea ice concentration data extending back to 1850 with a $1 / 4^{\circ} \times 1 / 4^{\circ}$ grid (Walsh et al. 2017) and passive microwave sea ice concentration data with $25 \mathrm{~km} \times 25 \mathrm{~km}$ resolution from November 1978 to December 2017 (Peng et al. 2013; Meier et al. 2017). All of these data are archived in the National Snow and Ice Data Center (NSIDC). In this work, sea ice area (SIA) is defined as the sum of the grid cell areas multiplied by the ice concentration. In summer (July-September), the SIA reaches the minimum value and its change can account for the change of the whole year by $66.7 \%$ (Wang and Ikeda 2001). Because the time series of the summer SIA is random and independent, and summer variations are easier to be captured than that in winter, this work mainly focuses on the analysis of Arctic sea ice in summer. The conclusions obtained in this study are insensitive to the choice of SIA rather than sea ice extent as the primary phenological variable.

Although the analysis of the full record (1850-2017) of summer SIA is desirable, the data are limited by gaps in observation availability, particularly prior to 1953 (Walsh et al. 2017). Furthermore, there is less variability in Arctic SIA prior to the satellite era, a significant part of which is due to the early twentieth-century warming (ETCW; Brennan et al. 2020). However, this longest gridded sea ice dataset has been used to successfully investigate and interpret various climate-related phenomena in previous studies (Wang and Ikeda 2000, 2001; Wang et al. 2005; Kim et al. 2019; Trusel et al. 2018; Bonan and Blanchard-Wrigglesworth 2020; Kolstad and Screen 2019; Klaus et al. 2018). It is noted that conclusions derived based on this dataset prior to 1953 need reliable data and careful analyses to support. Given the data uncertainty, especially in the mean values, we rely on sea ice anomalies (a deviation from mean) as our primary variable for studying the summer variability and have divided the entire observation period (18502017) into three subperiods to confirm the validity of our conclusions: 1850-1952, 1953-2017, and 1979-2017.

The sea ice thickness (SIT) and motion data in 1978-2017 are output from the Pan-Arctic Ice Ocean Modeling and Assimilation System (PIOMAS; Zhang and Rothrock 2003). The mean SIT and its spatial pattern agree well with satellite data obtained from 2003-09 ICESat (Schweiger et al. 2011). These curvilinear data cover the domain of $45^{\circ}-90^{\circ} \mathrm{N}$ with $360 \times 120$ grid points.

\section{2) AtMospheric VARIABLES}

Monthly sea level pressure (SLP), as well as near-surface air temperature (SAT), and surface wind are obtained from two twentieth-century reanalyses: The NOAA-CIRES (Cooperative Institute for Research in Environmental Sciences, University of 
TABLE 1. Large ensemble simulations.

\begin{tabular}{lcccl}
\hline \multicolumn{1}{c}{ Model } & Members & Years & Description & \multicolumn{1}{c}{ References } \\
\hline CESM1-CAM5 & 40 & $1920-2100$ & Historical forcing is used for the years & Kay et al. (2015) \\
GFDL CAM3 & 20 & $1920-2100$ & preceding 2006 and RCP8.5 forcing is & Sun et al. (2018) \\
GFDL-ESM2M & 30 & $1950-2100$ & used after 2006 & Rodgers et al. (2015) \\
CanESM2 & 50 & $1950-2100$ & & Kirchmeier-Young et al. (2017) \\
CSIRO-Mk3.6.0 & 30 & $1850-2100$ & & Jeffrey et al. (2013) \\
\hline
\end{tabular}

Colorado Boulder) Twentieth Century Reanalysis version 3 (1836-2015; 20CRv3; Slivinski et al. 2019) and European Centre for Medium-Range Weather Forecasts (ECMWF) twentieth-century reanalysis (1900-2010; ERA-20C; Poli et al. 2016). However, because ERA-20C cannot reproduce the DA pattern as the second-leading mode of SLP variability, we only show the results of $20 \mathrm{CRv} 3$ reanalysis data in this study.

\section{3) INDICES OF DOMINANT INTERNAL VARIABILITIES}

The NAO refers to a seesaw pattern between the intensities of the climatological Icelandic low and the Azores high with anomalous westerlies over the North Atlantic (Hurrell 1995). The station-based index of NAO (1865-2017) is based on the definition of Hurrell (1995) as the difference of normalized SLP between Lisbon, Portugal, and Stykkisholmur/Reykjavik, Iceland, which was obtained from the National Center for Atmospheric Research (NCAR) Climate Data Guide (Schneider et al. 2013).

The AMO is identified as the North Atlantic surface temperature oscillation with a period of 65-70 years and found to be primarily controlled by external forcing (Schlesinger and Ramankutty 1994; Haustein et al. 2019). As the AMO is influenced by associated climate changes and the analysis of variance can be dominated by the recent trends, to deal with purely Atlantic variability, the index is defined as the annual sea surface temperature (SST) anomalies averaged over the North Atlantic $\left(0^{\circ}-60^{\circ} \mathrm{N}, 0^{\circ}-80^{\circ} \mathrm{W}\right)$ for $1870-2017$, relative to the 1901-70 climatology but with the global mean SST removed using HadISST1.1 (Trenberth and Shea 2006).

As a long-lived pattern of Pacific SST variability, the standardized PDO index is derived as the leading PC of monthly SST anomalies in the North Pacific Ocean, poleward of $20^{\circ} \mathrm{N}$, provided by NOAA/NCDC (Zhang et al. 1997; Mantua et al. 1997). The monthly mean global average SST anomalies are removed to separate this pattern of variability from the "global warming" signal that may be present in the data.

\section{4) Climate model RUnS}

To assess the contribution of external forcing to the dominant modes of summer Arctic sea ice variability, the multiple large ensembles of climate simulations (LEs; Deser et al. 2020a; Table 1) and single-forcing ensembles (Deser et al. 2020b; Table 2) are employed. The new collection of initialcondition LEs generated with five Earth system models under historical forcing for the years preceding 2006 and RCP8.5 forcing after 2006 provides the opportunity to compare both internal variability and the forced response across different climate models in a consistent and coordinated manner (England 2021).The evolving roles of anthropogenic aerosols (AER) and greenhouse gases (GHG) in driving large-scale patterns of Arctic sea ice can be studied using "all-but-one-forcing" initial-condition large ensembles (single-forcing ensembles) with the Community Earth System Model version 1 (CESM1; Deser et al. 2020b); for example, the x-aer (ghg) run is identical to the historical run except that the emission of industrial aerosols (greenhouse gases) is held fixed at 1920 values.

\section{b. Methods}

The whole Arctic is divided into six subregions (Fig. 1) following Wang and Ikeda (2001). The time series of SIA anomalies are calculated by removing the monthly climatology in each region. All the time series of SIA in each region for the periods 1850-1952, 1953-2017, and 1979-2017 are detrended and then standardized before applying the EOF analysis to obtain the dominant modes of the summer Arctic sea ice variability (Wang and Ikeda 2000, 2001).

For the dominant modes of variability in SLP, AO is the first leading EOF mode of normalized SLP variabilities north of $70^{\circ} \mathrm{N}$ (Wu et al. 2006) and the second-leading mode was defined as the Arctic dipole anomaly (DA) pattern, which shows strong meridional wind anomalies (Wu et al. 2006; Wang et al. 2009).

Composite analysis is used to present the responses associated with a certain climate event such as the AO, DA, NAO, $\mathrm{AMO}$, and PDO by averaging the data over the years when the event occurred. To illustrate typical fields in the positive and negative phases of the event, we chose the cases with each index being greater (smaller) than one standard deviation as

TABLE 2. Single-forcing ensembles.

\begin{tabular}{cccccc}
\hline \hline Model & Expt & Members & Years & Description & Reference \\
\hline CESM1-CAM5 & x-aer & 20 & $1920-2080$ & $\begin{array}{c}\text { Anthropogenic aerosols fixed at 1920 } \\
\text { concentrations } \\
\text { Greenhouse gases fixed at 1920 } \\
\text { concentrations }\end{array}$ & Deser et al. (2020b) \\
\hline
\end{tabular}




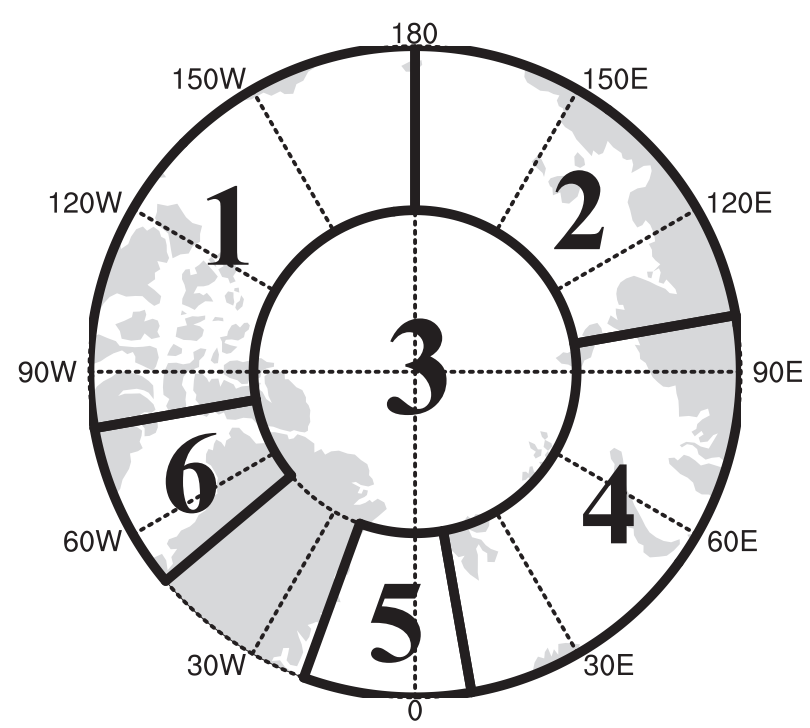

FIG. 1. The Arctic regions divided into six areas for use in this study, following Wang and Ikeda (2001): 1) the Beaufort and Chukchi Seas; 2) Laptev and East Siberian Seas; 3) central Arctic; 4) Barents and Kara Seas; 5) Greenland Sea; and 6) Baffin Bay.

extreme positive (negative) events (Table 3). The composite fields are constructed by averaging the standardized SLP, surface wind, SAT, and sea ice anomalies for these events. To account for the small samples available in this study, the Student's $t$ distribution was used to determine the statistical significance between the means of paired variables. Comparing the differences between the two means using the Student's $t$ test requires two independent samples of sizes $n_{1}$ and $n_{2}$, which possess means and standard deviations given by $\bar{x}_{1}$ and $\bar{x}_{2}$ and $s_{1}$ and $s_{2}$, respectively. Our null hypothesis $H_{0}$ is that the two samples are statistically indistinguishable from each other. To test $H_{0}$, we use the $t$ score given by Freund and Simon (1992)

$$
t=\frac{\bar{x}_{1}-\bar{x}_{2}}{\sqrt{\frac{\left(n_{1}-1\right) s_{1}^{2}+\left(n_{2}-1\right) s_{2}^{2}}{n_{1}+n_{2}-2}\left(\frac{1}{n_{1}}+\frac{1}{n_{2}}\right)}}
$$

which is the value of a random variable having the $t$ distribution with $n_{1}+n_{2}-2$ degrees of freedom. The null hypothesis is rejected if the two-tailed $t$ score exceeds the $95 \%$ confidence interval, and consequently the two samples are distinguishable.

The multiple linear regression is used to obtain the statistical relationships between the SIA variability and each dominant mode of climate variability. The following equations give a linear relationship between the time series of the PC1 (PC2) of EOF modes of summer SIA in six Arctic regions and the AO, DA, NAO, AMO, and PDO indices. Each time series of index is standardized and then detrended before being trained into the regression models:

$$
\hat{Y}_{\mathrm{PC} 1}=b_{0}+b_{1} \mathrm{AO}+b_{2} \mathrm{DA}+b_{3} \mathrm{NAO}+b_{4} \mathrm{AMO}+b_{5} \mathrm{PDO},
$$

and

$$
\hat{Y}_{\mathrm{PC} 2}=b_{0}+b_{1} \mathrm{AO}+b_{2} \mathrm{DA}+b_{3} \mathrm{NAO}+b_{4} \mathrm{AMO}+b_{5} \mathrm{PDO}
$$

where $\hat{Y}_{\mathrm{PC} 1}$ and $\hat{Y}_{\mathrm{PC} 2}$ are the expected value of $\mathrm{PC} 1$ and $\mathrm{PC} 2 ; b_{i}$ $(i=1, \ldots, 5)$ is the partial regression coefficient of PC1 (PC2) on each index; $b_{0}$ is the intercept. To examine the amount of total variability explained by the regression model, $R^{2}$, the coefficient of multiple determination, is calculated by

$$
R^{2}=1-\frac{\mathrm{ESS}}{\mathrm{TSS}}=\frac{\mathrm{RSS}}{\mathrm{TSS}}
$$

where TSS is the total sum of squares, TSS $=\sum\left(Y_{i}-\bar{Y}\right)^{2}$; ESS is the error sum of squares, ESS $=\sum\left(Y_{i}-\hat{Y}\right)^{2}$; and RSS is the regression sum of squares, $\mathrm{RSS}=\sum\left(\hat{Y}_{i}-\bar{Y}\right)^{2} ; Y_{i}$ is the observed PCs, $\hat{Y}_{i}$ is the expected value of PCs, and $\bar{Y}$ is the average of $Y_{i}$.

Based on $b_{i}(i=1, \ldots, 5)$, the standardized partial regression coefficients $b_{i}^{\prime}$ represent each index's contribution to the regression model based on standard scores. All the results are validated by the $F$ test:

$$
b_{i}^{\prime}=b_{i} \sqrt{\frac{\sum\left(X_{i}-\bar{X}\right)^{2}}{\sum\left(Y_{i}-\bar{Y}\right)^{2}}},
$$

where $X_{i}$ is the time series of AO/DA/NAO/AMO/PDO index, and $\bar{X}$ is the average of $X_{i}$. Compared with the correlation between summer Arctic SIA and each index in different seasons, summer AO, summer DA, winter NAO, annual mean AMO, and summer PDO shows higher correlation coefficient. Although there are quantitative differences among different seasons, the main results, especially the relationships between summer SIA and each index, are in good agreement regardless of seasons. Therefore, summer AO, summer DA, winter NAO, annual mean AMO, and summer PDO are used in this work. Summer (winter) results are produced by averaging over JulySeptember (January-March).

\section{Results}

\section{a. Variabilities in summer Arctic SIA}

\section{1) REgIONAL VARIABILITY}

The monthly SIAs (25-month running mean) in each Arctic region show pronounced interannual and decadal variabilities (Fig. 2). During the early twentieth century, an anomalous warming event with different timing and magnitude was well documented in each region and the trends of ETCW are calculated between 1918 and 1948, as suggested by Brennan et al. (2020). Except for the Laptev and East Siberian Seas and Baffin Bay, the trends of ETCW are smaller than that during 1953-2017. The declining trend has accelerated after 1953 and all Arctic regions have undergone the largest reduction of SIA over the recent four decades since 1979.

Since SIA reaches the minimum and its standard deviation (STD) reaches the maximum in summer (Wang and Ikeda 2001), 
the means and STDs of summer SIA in each region during the four periods of 1850-1952, 1918-48 (ETCW), 1953-2017, and 1979-2017 are calculated (Table 4). In each region, summer mean SIA are the highest during 1850-1952 (except for the central Arctic) and relatively low during ETCW, with the largest mean value in Baffin Bay relative to that for 1953-2017 and 1979-2017. Comparing the periods of 1953-2017 and 19792013, all Arctic regions have experienced the largest reduction of summer SIA over the recent decades since 1979 (Table 4, fifth column), which is consistent with the monthly linear trends (Fig. 2). The satellite era mean is nearly $20 \%$ smaller than the 1953-2017 mean in the Greenland Sea. For the whole Arctic, the summer mean SIA was $13.20 \times 10^{6}$ and $12.67 \times$ $10^{6} \mathrm{~km}^{2}$ for the period of 1953-2017 and 1979-2017, respectively. The decline accelerates $4.03 \%$ during the satellite era compared with the 1953-2017 mean. However, in the central Arctic, the mean SIAs for 1850-1952 involving ETCW are even lower than that during 1979-2017. This systematic error may be due to a lack of high-quality sea ice observations pre-1953, especially for the high central Arctic Ocean, and the satellite passive microwave sensing techniques after1979 can identify some small open water within the pack ice, leading to lower summer ice concentrations. Thus, the mean values before 1953 must be interpreted with a degree of caution (Brennan et al. 2020).

The variability, as represented by the detrended STD in most Arctic regions, has increased from 1850-1952 to 19532017, and from 1953-2017 to 1979-2017, indicating an increase in both the interannual and decadal variability (except for the Greenland Sea and Baffin Bay). However, Brennan et al. (2020) pointed out that this sea ice dataset shows less interannual variability during the instrumental era, a significant part of which is due to the underestimation of the magnitude of ETCW in the Arctic. From this analysis, the Beaufort and Chukchi Seas $\left(0.18 \times 10^{6} \mathrm{~km}^{2}\right)$ had the smallest STD during ECTW compared with other periods. The largest increase $(19.69 \%)$ in STD of $0.35 \times 10^{6} \mathrm{~km}^{2}$ since 1979 occurred in the central Arctic compared with 1953-2017. For the whole Arctic, the STD was $1.39 \times 10^{6} \mathrm{~km}^{2}$ during 1953-2017 and increased by $18 \%$ for $1979-2017$.

\section{2) EOF ANALYSIS OF ARCTIC SUMMER SIA}

The leading EOF mode of summer Arctic SIA exhibits the in-phase fluctuation-Arctic Sea Ice Oscillation (ASIO; Wang and Ikeda 2000) in the six regions (except for the Greenland Sea during 1953-2017 and 1979-2017) — and the second mode captures a dipolar pattern with out-of-phase variabilities between the Pacific Arctic and the Atlantic Arctic (Figs. 3a-c), which is consistent with results given by Wang and Ikeda (2000, 2001) for the period of 1901-95. There are similar patterns among the periods of 1953-2017 and 1979-2017 (Figs. 3b,c). However, during 1850-1952, the variation in Baffin Bay keeps in phase with that in the Pacific Arctic in the second mode. Compared with the contributions of each mode for each period, the variance of ASIO (first mode) decreased for the recent decades $(43.4 \% \rightarrow 43.9 \% \rightarrow 31.0 \%)$, while the second mode has no obvious change $(22.7 \% \rightarrow 20.8 \% \rightarrow 22.9 \%)$. This indicates that the ratio of mode 2 (mainly representing dynamical effect) to mode 1 (mainly representing thermodynamical effect) increased
TABLE 3. The positive and negative events for summer AO, summer DA, winter NAO, annual mean AMO, and summer PDO indices ( + for positive events; - for negative events).

\begin{tabular}{|c|c|c|c|c|c|c|c|c|c|}
\hline \multicolumn{2}{|c|}{$\mathrm{AO}$} & \multicolumn{2}{|c|}{ DA } & \multicolumn{2}{|c|}{ NAO } & \multicolumn{2}{|c|}{ AMO } & \multicolumn{2}{|c|}{ PDO } \\
\hline+ & - & + & - & + & - & + & - & + & - \\
\hline 1882 & 1851 & 1851 & 1853 & 1868 & 1867 & 1878 & 1883 & 1902 & 1920 \\
\hline 1890 & 1864 & 1864 & 1874 & 1882 & 1870 & 1927 & 1884 & 1913 & 1933 \\
\hline 1898 & 1872 & 1872 & 1886 & 1894 & 1881 & 1931 & 1894 & 1926 & 1948 \\
\hline 1909 & 1894 & 1876 & 1899 & 1903 & 1888 & 1932 & 1902 & 1934 & 1949 \\
\hline 1924 & 1903 & 1877 & 1905 & 1907 & 1895 & 1933 & 1903 & 1936 & 1950 \\
\hline 1925 & 1905 & 1879 & 1907 & 1908 & 1899 & 1936 & 1904 & 1940 & 1952 \\
\hline 1928 & 1907 & 1880 & 1911 & 1910 & 1900 & 1937 & 1905 & 1941 & 1955 \\
\hline 1932 & 1911 & 1893 & 1915 & 1913 & 1901 & 1938 & 1912 & 1983 & 1961 \\
\hline 1933 & 1915 & 1894 & 1916 & 1920 & 1917 & 1944 & 1913 & 1987 & 1962 \\
\hline 1937 & 1930 & 1895 & 1922 & 1921 & 1924 & 1948 & 1914 & 1992 & 1970 \\
\hline 1938 & 1934 & 1901 & 1923 & 1927 & 1929 & 1949 & 1918 & 1993 & 2001 \\
\hline 1942 & 1943 & 1902 & 1928 & 1934 & 1932 & 1951 & 1919 & 1995 & 2008 \\
\hline 1944 & 1950 & 1912 & 1929 & 1989 & 1936 & 1952 & 1920 & 1997 & 2010 \\
\hline 1945 & 1951 & 1914 & 1934 & 1990 & 1940 & 1953 & 1922 & 2015 & 2011 \\
\hline 1946 & 1959 & 1954 & 1941 & 1994 & 1941 & 1955 & 1923 & & 2012 \\
\hline 1947 & 1960 & 1958 & 1946 & 1995 & 1947 & 1960 & 1972 & & \\
\hline 1952 & 1965 & 1968 & 1950 & 2014 & 1955 & 1999 & 1973 & & \\
\hline 1953 & 1968 & 1976 & 1955 & 2015 & 1958 & 2005 & 1974 & & \\
\hline 1955 & 1977 & 2002 & 1959 & & 1960 & 2006 & 1982 & & \\
\hline 1967 & 1978 & 2005 & 1961 & & 1963 & 2007 & 1984 & & \\
\hline 1975 & 1979 & 2006 & 1965 & & 1964 & 2008 & 1985 & & \\
\hline 1976 & 1985 & 2007 & 1975 & & 1965 & 2010 & 1986 & & \\
\hline 1988 & 1990 & 2010 & 1979 & & 1966 & 2011 & 1991 & & \\
\hline 1989 & 1993 & 2014 & 1981 & & 1969 & 2012 & 1992 & & \\
\hline 1994 & 2015 & & 1984 & & 1985 & & 1993 & & \\
\hline 2003 & & & 1990 & & 1987 & & 1994 & & \\
\hline & & & 1996 & & 2010 & & & & \\
\hline & & & 2013 & & & & & & \\
\hline
\end{tabular}

in recent decades $(0.52 \rightarrow 0.47 \rightarrow 0.74)$, implying the increasing importance of the dynamical effect (mode 2).

Both time series of PC1 and PC2 (i.e., eigenfunctions) exhibit interannual and decadal variabilities (Figs. 3d-i). The positive (negative) values of $\mathrm{PC1}$ time series correspond to a decrease (increase) in SIA in each region (except for the Greenland Sea during 1953-2017 and 1979-2017). It is noted that SIA in all Arctic regions experienced a positive phase during 1935-45 due to the1930s' Arctic warming (Callendar 1961), leading to significant ice melting in the Arctic. At the same time, PC2 exhibited more negative phases during the 1920s-1940s, based on Fig. 3a, indicating that SIA in the central Arctic and the Barents, Kara, and Greenland Seas (areas 3, 4, and 5) experienced reduction, while SIA in the Beaufort, Chukchi, Laptev, and eastern Siberian Seas and in Baffin Bay (areas 1, 2, and 6) increased. This indicates that both PC1 and PC2 contributed to loss of sea ice due to ETCW.

During the 1950 s to the 2000 s, PC1 exhibited a shift from positive to negative phase (Fig. 3f). Since the 2010s, PC1 experienced a larger positive phase than during the $1950 \mathrm{~s}$ (i.e., sea ice reduction except for the Greenland Sea; Figs. 3f,h). This indicates that PC1 experienced multidecadal change. Compared with previous decades, with more significant positive events since 2007, the reduction 


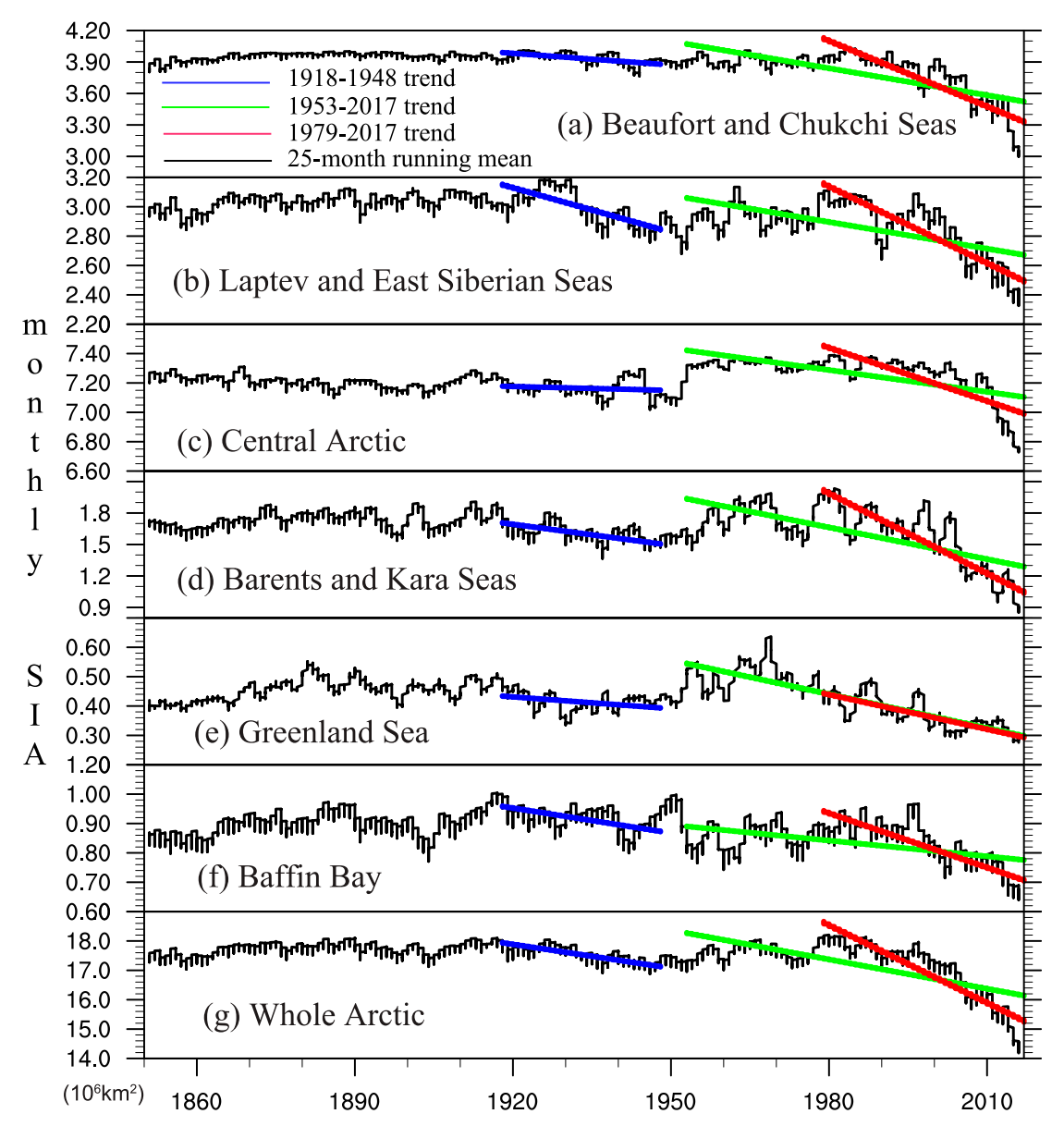

FIG. 2 Monthly SIA (25-month running mean is applied) over six Arctic regions and the whole Arctic for the periods of 1850-2017 $\left(10^{6} \mathrm{~km}^{2}\right)$ with trends for 1918-48 (blue), 19532017 (green), and 1979-2017 (red).

of SIA was accelerated, consistent with the variabilities of mean SIA in each region (Fig. 2 and Table 4).

The PC2 exhibited both interannual and multidecadal variabilities as well. For the early stage (1850-1952) the negative phase prevailed during the 1850s-1900s and 1920s-40s [less ice in the central Arctic due to ETCW; see Fig. 3a (in red) and Fig. 3e]. The positive phase dominated from the 1960s to the 1970s [more ice in the central Arctic; see Fig. 3a (in red) and Fig. 3g]. Wang et al. (2005) pointed out that before (after) the 1960s, the sea ice anomaly in the Nordic seas (central Arctic) led the central Arctic (Nordic seas) on the decadal time scales. The satellite era starts with more positive phases (Fig. 3i). PC2 determines the out-of-phase changes between the regions of the Beaufort and Chukchi, Laptev, and East Siberian Seas (areas 1 and 2) and the regions of the central Arctic, Barents, Kara, and Greenland Seas, and Baffin Bay (areas 3, 4, 5, and 6), as shown in Figs. $3 b$ and $3 c$ (in red). Therefore, there was negative anomaly (less ice cover) in the Pacific Arctic and positive anomaly (more ice cover) in the Atlantic Arctic for the positive phase, and the opposite scenario occurred for the negative phase. Especially after 1985, the Pacific Arctic lost more ice, while the Atlantic Arctic gained more ice, due to the DA's advection of sea ice from the Pacific and central Arctic to the Atlantic Arctic (Wu et al. 2006; Wang et al. 2009, 2014). This reversal in phase in the 1950s was captured using wavelets analysis of the same dataset for the period 1901-95 [see Fig. 6, top panel, of Wang et al. (2005)].

\section{3) REGRESSION OF ATMOSPHERIC CIRCULATION ON THE SEA ICE PCS}

Based on the summer Arctic sea ice PCs, regression analyses were performed to illustrate how the PC1 and PC2 are related to atmospheric circulation anomalies (SLP, surface winds, and SAT from 20CRv3; Figs. 4a-d). Because of the data uncertainty prior to 1953 and the fact that the patterns during 19792015 are similar to those during 1953-2015, only the results for the 1979-2015 periods are shown here.

Figures $4 \mathrm{a}, 4 \mathrm{c}$, and $4 \mathrm{e}$ show the standardized SLP, surface wind, SAT, and sea ice anomalies obtained from a linear regression on the PC1. With anticyclonic (cyclonic) wind anomalies, the positive (negative) SLP anomalies dominate the whole central Arctic and nearly the entire Beaufort and Chukchi Seas. At the same time, there are negative (positive) SLP anomalies in the surrounding regions. The associated anticyclonic (cyclonic) surface wind anomalies would further support the convergence (divergence) 
TABLE 4. Regional mean and detrended standard deviation (STD; $10^{6} \mathrm{~km}^{2}$ ) during 1850-1952, 1918-48, 1953-2017, and 1979-2017.

\begin{tabular}{lccccccccc}
\hline \hline & \multicolumn{4}{c}{ Mean } & & \multicolumn{3}{c}{ Detrended STD } \\
\cline { 2 - 4 } \cline { 7 - 9 } & $1850-1952$ & $1918-48$ & $1953-2017$ & $1979-2017$ & & $1850-1952$ & $1918-48$ & $1953-2017$ & $1979-2017$ \\
\hline 1. Beaufort and Chukchi Seas (B\&C) & 3.55 & 3.52 & 3.10 & 2.91 & & 0.20 & 0.18 & 0.49 & 0.58 \\
2. Laptev and East Siberian Seas (L\&E.S) & 2.47 & 2.37 & 1.96 & 1.85 & & 0.32 & 0.39 & 0.48 & 0.55 \\
3. Central Arctic (C.Ar) & 6.87 & 6.80 & 7.04 & 6.97 & & 0.19 & 0.20 & 0.29 & 0.35 \\
4. Barents and Kara Seas (B\&K) & 0.78 & 0.63 & 0.61 & 0.53 & & 0.20 & 0.22 & 0.28 & 0.28 \\
5. Greenland Sea (Gre.) & 0.29 & 0.25 & 0.27 & 0.22 & & 0.057 & 0.057 & 0.090 & 0.065 \\
6. Baffin Bay (Baf) & 0.41 & 0.47 & 0.25 & 0.21 & & 0.17 & 0.15 & 0.10 & 0.096 \\
7. Total Arctic & 14.50 & 14.23 & 13.20 & 12.67 & & 0.82 & 0.87 & 1.39 & 1.64 \\
\hline
\end{tabular}

of existing sea ice. The SLP anomalies distribution is more like the SLP patterns during the $-\mathrm{AO}$ and $-\mathrm{NAO},+\mathrm{AMO}$, and $-\mathrm{PDO}$ (Figs. 5a-c, 7a,b, 8b,c, and 9b,c). Similarly, the warming over most Arctic regions is shown in SAT anomalies (Figs. 4c, 5e,f, 7c, d, 8e,f, and 9e,f). Due to both thermodynamical and dynamical effects, summer sea ice declined except for the Greenland Sea (Fig. 4e).

Regression of SLP on the PC2 shows the DA pattern with a positive (negative) center located in the Canadian Arctic Archipelago (CAA) of the western Arctic and in the Laptev and East Siberian Seas of the eastern Arctic (Fig. 4b), mimicking the DA-derived meridional wind anomaly (Figs. 6a-c), which enhances dynamical transport of sea ice from the Pacific Arctic to the Atlantic sector, and out of the Arctic Ocean through the Atlantic side (Lei et al. 2018). The warming anomalies cover most Arctic regions and cooling anomalies cover the Barents and Greenland Seas (Fig. 4d), where meridional wind anomalies bring more cold air from the higher latitudes. This SAT anomalies pattern is nearly the same as the distribution during +DA (Figs. 6d-f). Corresponding to the second EOF mode of summer Arctic sea ice (Figs. 3b,c), there

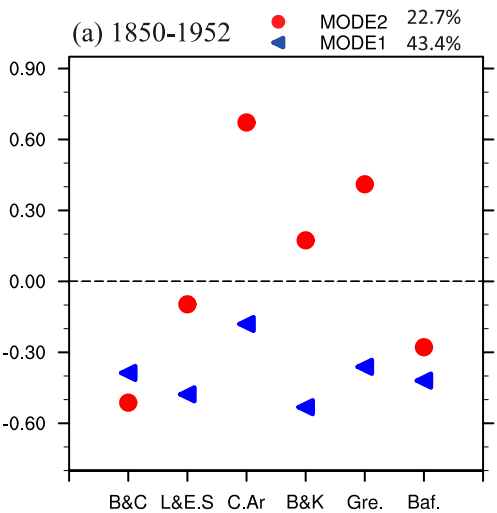

(d) PC1: 1850-1952

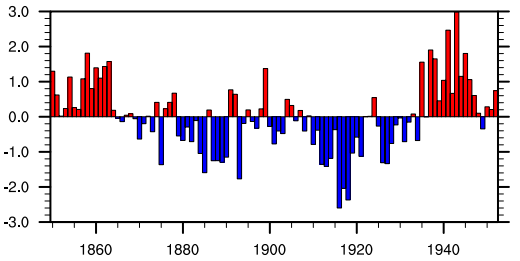

(e) PC2: $1850-1952$

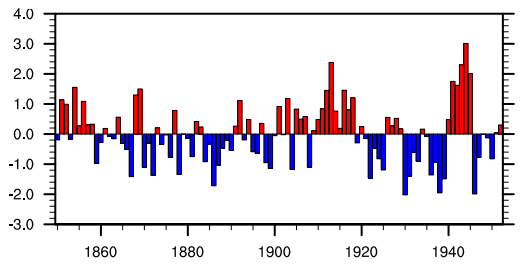

(b) $1953-2017: \quad$ MODE2 $20.8 \%$

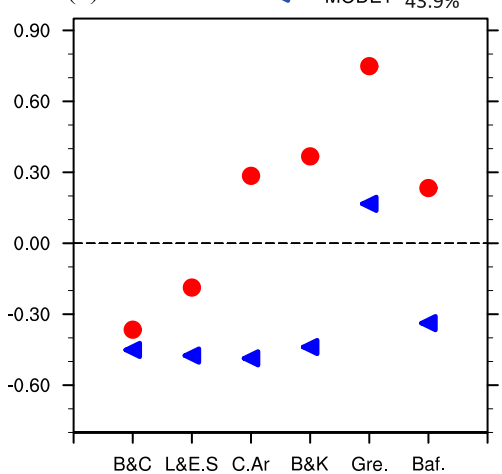

(f) PC1: 1953-2017

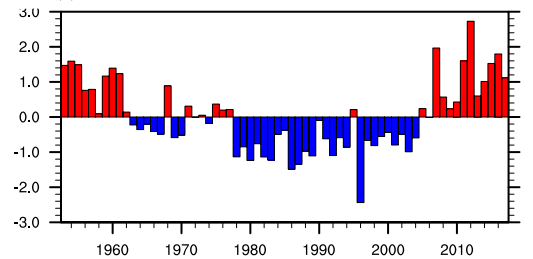

(g) PC2: 1953-2017

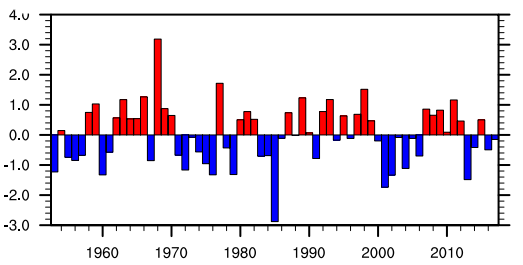

(c) $1979-2017 \quad$ MODE2 $22.9 \%$

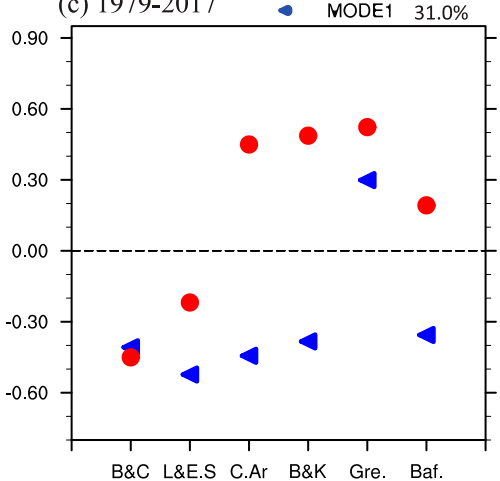

(h) PC1: 1979-2017

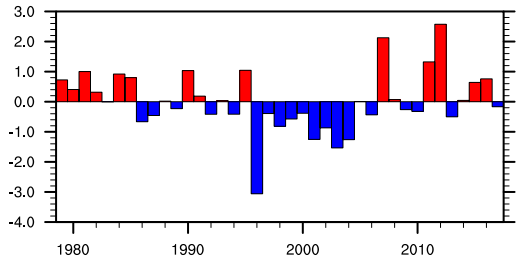

(i) PC2: 1979-2017

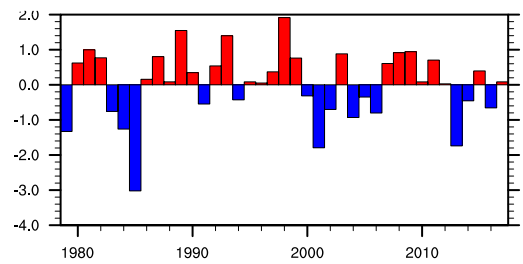

FIG. 3. The spatial distributions (eigenvectors) of the first two leading EOF modes of summer SIA in six Arctic regions for (a) 18501952, accounting for $43.4 \%$ and $22.7 \%$ of the total variance, respectively; (b) $1953-2017$, accounting for $43.9 \%$ and $20.8 \%$ of total variance, respectively; and (c) 1979-2017, accounting for 31.0\% and $22.9 \%$ of the total variance, respectively. Also shown are the time series of PC1 and PC2, respectively, for (d),(e) 1850-1952, (f),(g) 1953-2017, and (h),(i) 1979-2017. 
(a) SLP

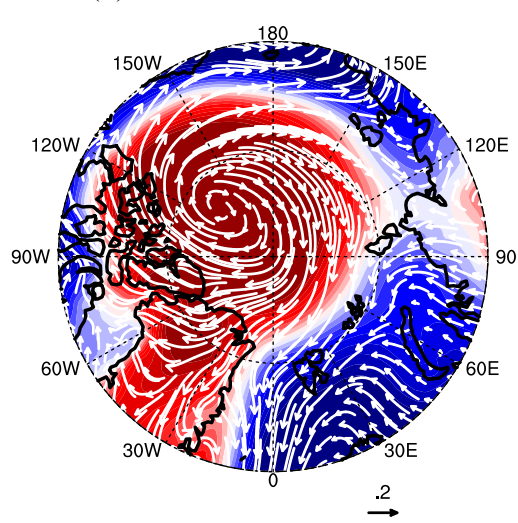

(b) SLP

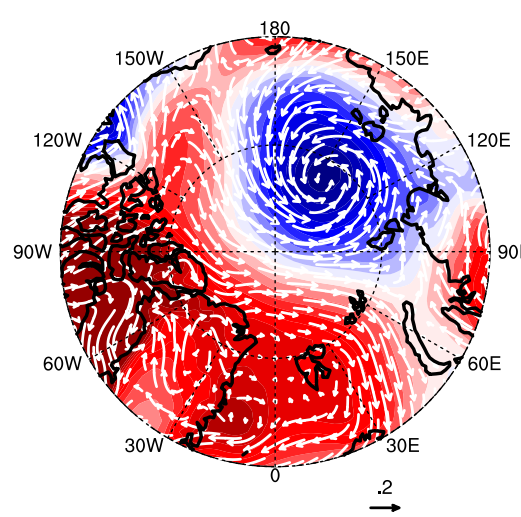

$\stackrel{.2}{\longrightarrow}$ (c) SAT

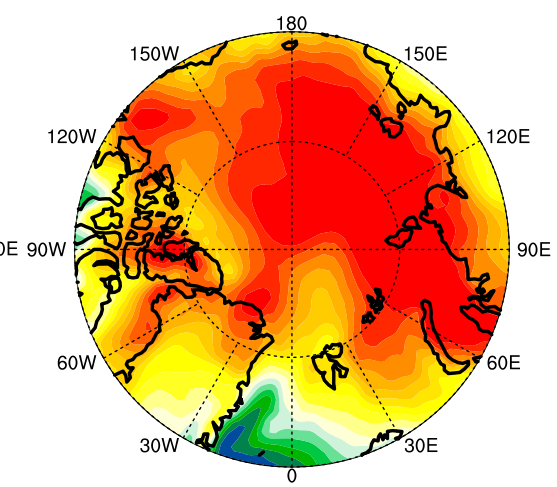

(d) SAT

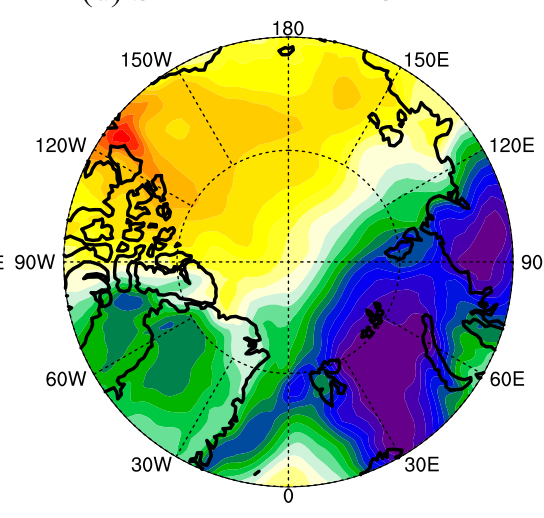

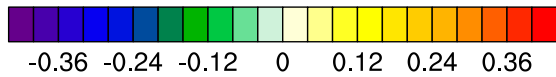

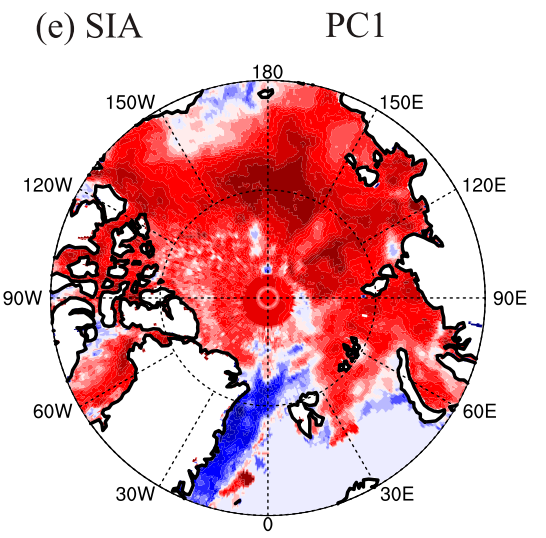

(f) SIA

PC2

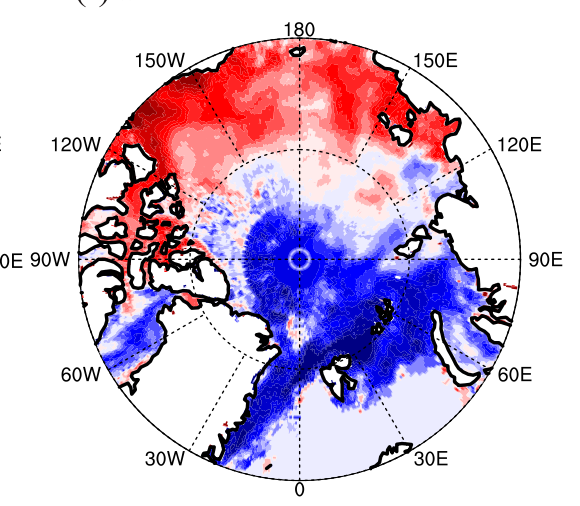

$\begin{array}{lllllll}-0.18 & -0.12 & -0.06 & 0 & 0.06 & 0.12 & 0.18\end{array}$

$\begin{array}{lllllll}-0.36 & -0.24 & -0.12 & 0 & 0.12 & 0.24 & 0.36\end{array}$

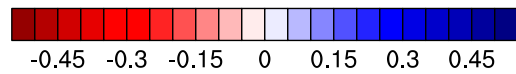

FIG. 4. Regression maps of standardized (left) SLP and surface wind, (center) SAT and (right) SIA on the summer Arctic SIA (a),(c),(e) PC1 and (b),(d),(f) PC2 for 1979-2017. The vector scale (.2) is normalized wind speed with no unit.

is a dipolar pattern with out-of-phase sea ice variabilities between the Pacific Arctic and the Atlantic Arctic (Fig. 4f), which is similar to the distribution during +DA (Figs. 6h,i).

Therefore, the out-of-phase sea ice variability indicates both thermodynamical and dynamical effects. Dynamically, the coastal regions of the Pacific sector and Russia sector of the Arctic Ocean are considered the ice factory to provide sea ice subsequently drifting northward, which is advected into the transpolar drift stream (TDS), and farther to the North Atlantic. This is why DA is more dynamically effective to cause this dipolar (out of phase) SIA change between the Pacific and Atlantic Arctic (Wang et al. 2009; Zhang 2015).Thermodynamically, the cooling anomalies in the Atlantic Arctic, which are more obvious in the Barents Sea, also slow down the ice melting in summer (Lei et al. 2018), while the Pacific Arctic sea ice becomes less with intensified warming anomalies due to positive ice-ocean albedo feedback (Zhang et al. 2008; Wang et al. 2014).

\section{b. Association between summer Arctic SIA and dominant internal variabilities of climate system}

To better understand the relationship between Arctic SIA variability and dominant internal variability of the climate system over each region, we conducted a composite analysis based on each index of dominant internal variability for three periods of 1850-1952, 1953-2017, and 1979-2017.

\section{1) Composite AnAlysis BASED ON AO AND DA}

Since there are negative (positive) SLP anomalies over the whole Arctic region for the extreme positive (negative) AO phase (see Table 3), the SLP difference between the positive and negative AO phases shows an annular structure with statistically significant negative anomalies (Figs. 5a-c). There are no significant changes between different time periods.

Corresponding to the spatial distribution of $\mathrm{AO}$, the composite of summer SAT exhibits cooling anomalies in most Arctic regions (except for the period of 1850-1952) for the positive AO events (Figs. 5d-f) and the summer cooling significantly intensified in the Greenland, Barents, and Kara Seas during 1979-2017.

It has been found that the enhanced ridging over the Arctic Ocean promotes subsidence-induced adiabatic warming and moistening in the lower troposphere (e.g., Sedlar and Tjernström 2017; Ding et al. 2019; Serreze et al. 2019; Papritz 2020). Dynamically, the transport of energy into and away from the Arctic is related to annular-type fluctuations in the Northern 
(a) SLP

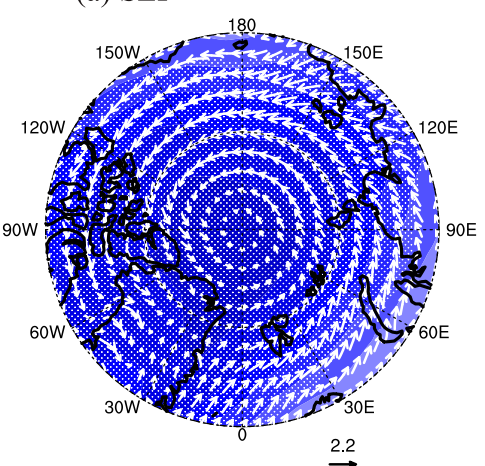

(d) SAT

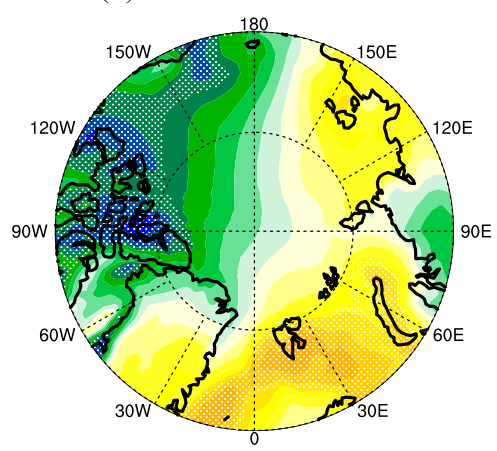

(g) SIA

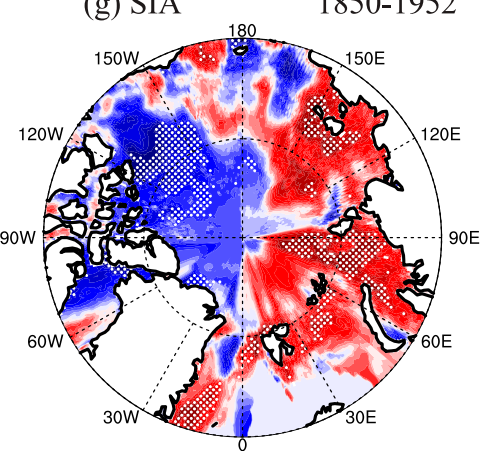

(b) SLP

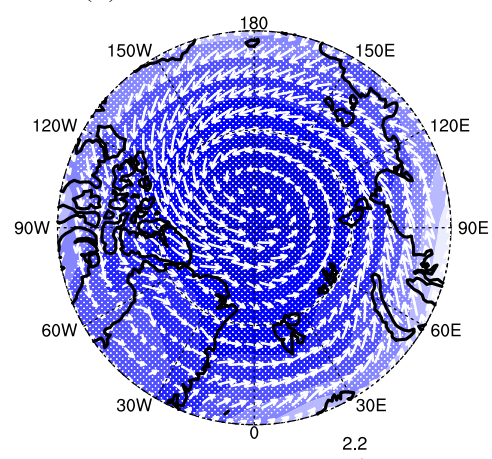

(e) SAT

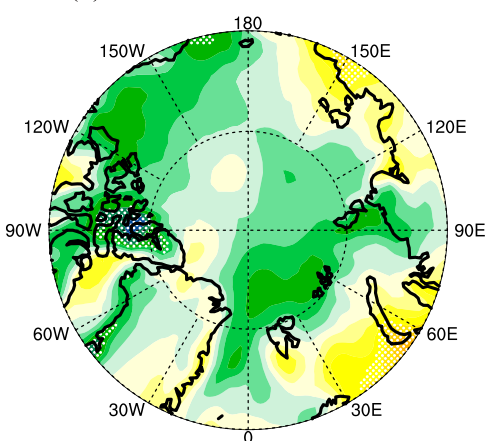

(h) SIA

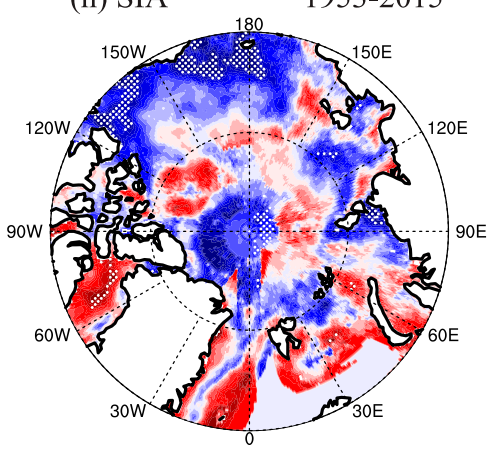

(c) SLP

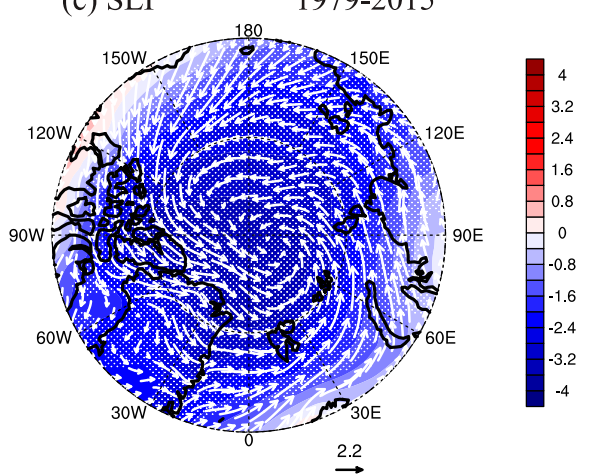

(f) SAT

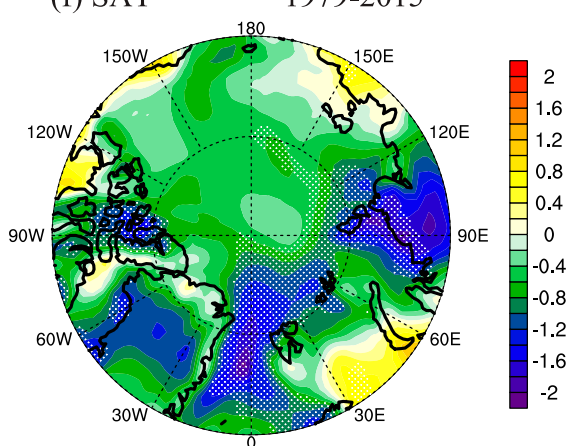

(i) SIA

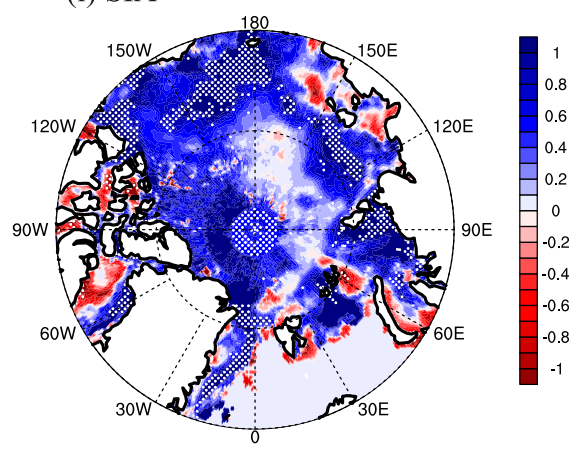

FIG. 5. The differences of composited (top) SLP and surface wind, (middle) SAT, and (bottom) SIA anomalies between positive summer AO events and negative summer AO events during (a),(b),(g) 1850-1952, (b),(e),(h) 1953-2015, and (c),(f),(i) 1979-2015. The regions above $95 \%$ confidence level are stippled. The wind vector scale (2.2) is normalized wind speed with no unit. The same normalized wind speed applies to Figs. 6-9.

Hemisphere atmospheric circulation (Olonscheck et al. 2019). During positive (negative) summer AO, the cyclonic (anticyclonic) wind anomalies, which weaken (strengthen) the Beaufort high (i.e., the TDS), restrict (promote) the sea ice advection out of the Arctic by divergence (convergence) and southward (northward) Ekman drift of the ice in the marginal zone, resulting in sea ice retention (loss) (Ogi and Wallace 2007; Ding et al. 2019; Serreze et al. 2019). Figures 5g-i show the composite SIA under thermodynamical and dynamical effects during summer AO events. Although SIA anomaly in Baffin Bay and the Greenland, Barents, and Kara Seas shows negative values during 1953-2015, there are positive anomalies in most Arctic regions for 1979-2015 related to the intensified cooling anomalies for the summer positive AO (Fig. 5f).
The - AO pattern is similar to the regression pattern of sea ice on the Arctic sea ice PC1 (Fig. 4e).

The composite SLP based on the DA index (Table 3) displays a conspicuous seesaw pattern, with positive (negative) SLP anomalies over the CAA and negative (positive) SLP anomalies over the Laptev and Kara Seas during the positive (negative) DA events (Figs. 6b,c). One center is located over the Greenland Sea and the other is over the Laptev Sea, which mimics the SLP pattern of Arctic sea ice PC2 using the regression method (Fig. 4b). The whole pattern rotates $90^{\circ}$ counterclockwise for 1850-1952, during which period more events occurred (Table 3; making up $1 / 3$ of the total events). The anomaly amplitude is larger during the period of 1979-2017, indicating the enhancement of DA since 1979. 
(a) SLP

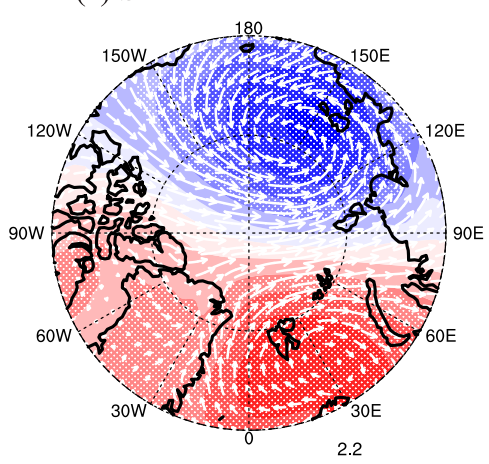

(d) SAT
$1850-1952$

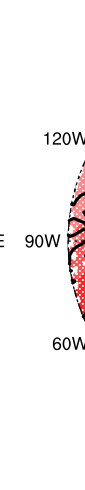

(b) SLP

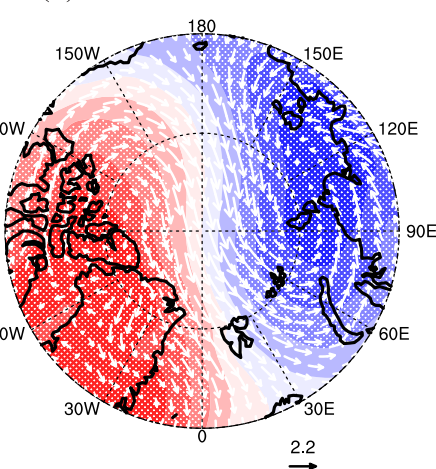

(e) SAT

1953-2015

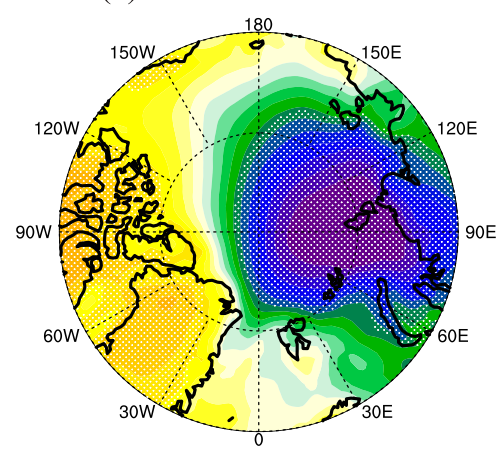

(g) SIA

1850-1952

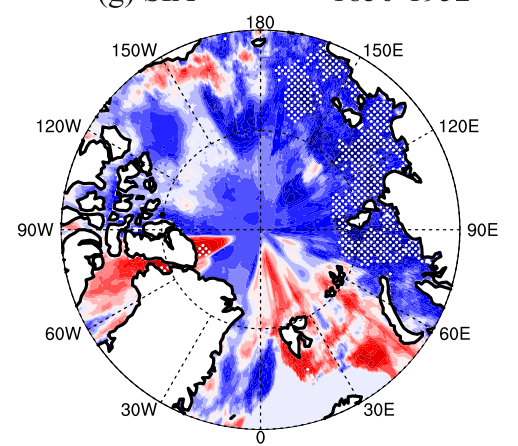

(c) SLP
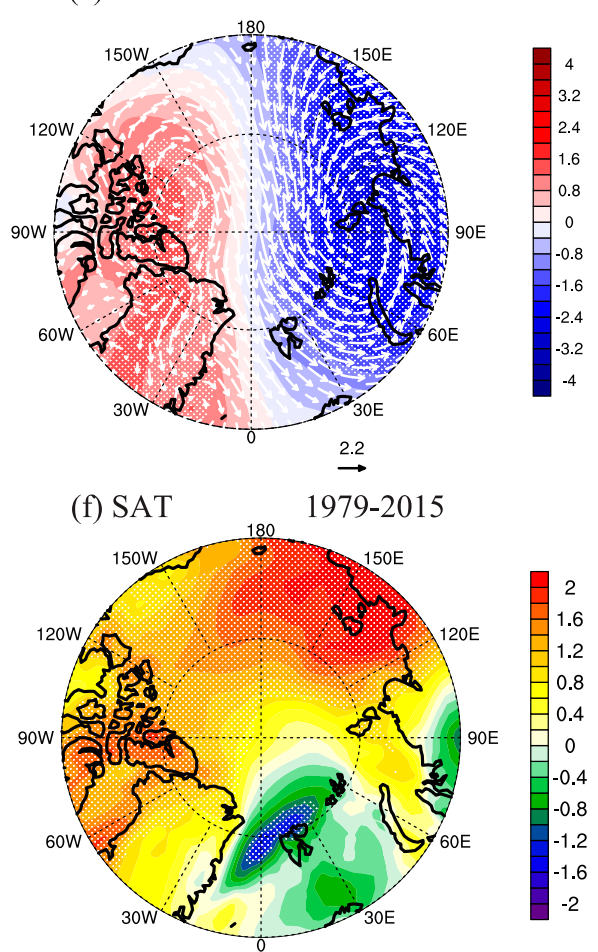

(i) SIA

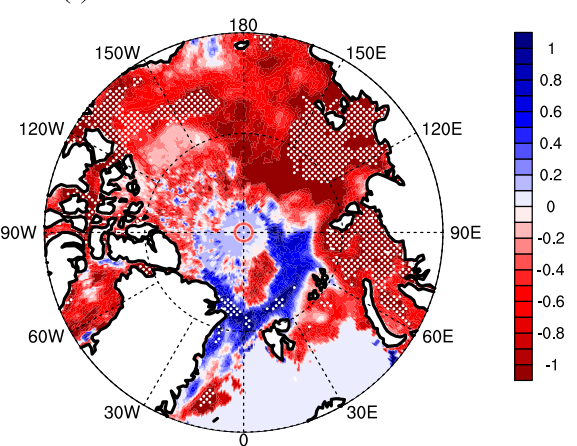

FIG. 6. As in Fig. 5, but for summer DA events.

Since the spatial distribution of SLP anomalies and the associated meridional wind (Figs. 6a-c) during positive (negative) DA events is favorable for the cold air outbreak downstream (upstream) of the TDS, there are noticeable dipole structures with cooling (warming) anomalies over the Barents, Kara, and Greenland Seas and warming (cooling) anomalies over other Arctic regions (Hegerl et al. 2018; Figs. 6e,f). It is noted that the cooling anomalies are significant for 1850-1952, which occupied almost the whole eastern Arctic Ocean and then became weaker and even turned to be positive values in some areas after 1953. Because the DA-pattern of SLP intensified in recent decades (1979-2017; Fig. 6c), the SAT differences between positive and negative DA events show that the warming anomalies intensify and even extend to the Kara Sea, although they are not statistically significant (Fig. 6f). The intensified Arctic warming anomalies partially contribute to the Arctic amplification in the last four decades (Hegerl et al. 2018). From this point of view, the thermodynamical effect of $+\mathrm{DA}$ is that the meridional wind anomalies advent much warmer air to the Pacific Arctic from the low-latitude northern Pacific Ocean.

The composite of sea ice concentration indicates that during the positive phase of DA, sea ice is advected from the Pacific Arctic and central Arctic to the Atlantic Arctic by anomalous meridional winds (Figs. 6a-c and $6 \mathrm{~g}-\mathrm{i}$ ), while during the negative DA phase sea ice would be retained in the Pacific Arctic and Central Arctic. Therefore, during the positive phase of DA, the SAT warming on the Pacific side is intensified (Figs. 6d-f) due to the positive ice-ocean albedo feedback (Zhang et al. 2008; Wang et al. 2005, 2014). That is to say, in the ice zone, the SAT would remain near the freezing point to maintain the heat balance between ocean and sea ice through ice melting. However, it would increase to a higher degree for 
the ice-free region. Although there are anomalous positive values in the most Arctic regions, except for the Barents Sea and Baffin Bay for 1850-1952 (Fig. 6g), the patterns for 19532015 and 1979-2015 are more reasonable (Figs. 6h,i). It is also noticed that the spatial pattern of composite sea ice anomalies for the positive DA is similar to the regression pattern of sea ice on the Arctic sea ice PC2, except for Baffin Bay and the Greenland and Kara Seas (Fig. 4f). Impacted by the Arctic amplification that drove the positive ice-albedo feedback in the last four decades, the SIA decreases over the Pacific Arctic were enhanced during positive DA events for the period of 1979-2015 (Fig. 6i).

\section{2) COMPOSITE ANALySIS BASED ON THE NAO}

Since positive NAO reflects the below-normal SLP across the high latitudes of the North Atlantic, it can be regarded as a subset of the spatially broader AO (Deser et al. 2000). The preceding winter NAO's impact on summer Arctic sea ice is part of a quasi-decadal Arctic climate (atmosphere-ice-ocean) cycle, as summarized in Fig. 13 of Wang et al. (2005).

For 1865-1952, the composite SLP shows systematic errors with positive anomalies over the Arctic (in both the 20CRv3 and ERA-20C datasets; not shown here). During 1953-2015 and 1979-2015, positive NAO is characterized by a weakening of the surface high pressure and the intensification of the cyclonic circulation in the eastern Arctic Ocean (Figs. 7a,b; Zhang et al. 2000). Based on this NAO pattern, anomalously low pressure over Novaya Zemlya and above normal SLP over Svalbard lead to a slightly weakened SLP gradient, which would further reduce the winds across the northern border of the Barents Sea (Koenigk et al. 2009). The associated cyclonic surface wind anomalies in the eastern Arctic Ocean support a cyclonic pattern of surface wind anomalies that cause divergence of existing sea ice (Strong and Magnusdottir 2010). However, compared with these two periods of 1953-2015 and 1979-2015, the SLP composite presents a weaker zonal flow and an enhanced meridional flow out of the Arctic (Overland et al. 2011; Sedlar and Tjernström 2017) for 1979-2015 (Fig. 7b) due to the different location of maximum/minimum center.

When the winter Icelandic low is intensified (weakened) - that is, when winter NAO is positive (negative) - the above-normal (below-normal) warm Gulf Stream Extension water is advected northward to the Nordic seas, entering the Arctic through the Fram Strait and the Barents Sea (Wang et al. 2005). The composite SAT shows warming anomalies among all Arctic seas during 19532017 (Fig. 7c) related to enhanced atmospheric (Li et al. 2014) and oceanic heat transports during the positive NAO. There is cold air that is transported from the central Arctic by the enhanced meridional wind anomalies in the Barents Sea (Fig. 7b); the warming becomes weaker and the cooling anomalies extend to the Barents Sea for 1979-2015 (Fig. 7d). It is noted, however, that with annulartype SLP anomalies, the warming/cooling anomalies associated with winter NAO are opposite of those for AO (Figs. 5d-f) and would lead to different variabilities of summer sea ice (Figs. 7e,f).

The positive NAO events result in reduction of SIA over most Arctic regions, except for the eastern central Arctic during 19792017 (Figs. 7e,f; Zhang et al. 2000; Alexander et al. 2004; Koenigk et al. 2009; Strong et al. 2009). The weakened wind anomalies across the northern border of the Barents Sea and associated cyclonic sea ice circulation anomalies (Figs. 7a,b) that advect sea ice and diverge existing sea ice into the high Arctic (Figs. 7e,f), would dynamically contribute to changes in SIA. Thermodynamically, the +NAO-driven poleward heat transport in the North Atlantic and the warming SAT anomalies over the most Arctic regions exert an influence on the formation and melting of sea ice. Correspondingly, for the positive NAO, the basal ice growth rates are depressed throughout the eastern North Atlantic.

It is noticed that the spatial pattern of composite sea ice anomalies is similar to the regression pattern of sea ice on the Arctic sea ice PC1 (Figs. 4e and 7e). The most significant change for the two periods is that there is more sea ice in the eastern central Arctic, which is consistent with the sea ice advection by strong meridional wind anomalies during 1979-2015 (Fig. 7b).

\section{3) COMposite AnAlysis BASED ON THE AMO}

The AMO is related to the large-scale multidecadal fluctuations in the Atlantic SST and is highly correlated with Arctic temperature changes (Chylek et al. 2009). The main difference from the traditional definition is that this AMO index (Trenberth and Shea 2006) discriminates between variabilities arising from the thermohaline circulation and other phenomena with North Atlantic origins, and global anthropogenic changes. The composite SAT for the positive AMO exhibits the overall Arctic warming (except for the cooling anomalies in the Beaufort and Chukchi Seas during 1870-1952), making up $43.3 \%$ of the total events (Table 3), and the amplitude became larger in recent decades (1979-2017), indicating the stronger positive AMO events (Figs. 8d-f). At the same time, during the negative AMO events there are cooling anomalies over the entire Arctic.

During 1870-1952, there are negative SLP anomalies among most Arctic regions (except for the East Siberian Sea) during the positive AMO events (Fig. 8a). However, for the recent decades, the dipole SLP anomalies, similar to the positive DA (Figs. 6a-c), enhanced transpolar (meridional) wind anomalies that intensified the TDS during 1979-2015 (Figs. 8b,c).

With the warming effects impacting the whole Arctic during positive AMO events (Figs. 8d-f), the SIA declined across most Arctic regions during the recent six decades (Figs. 8h,i). For the western side of the central Arctic and Greenland and Barents Seas, the positive AMO triggers meridional sea ice advection out of the Pacific Arctic (Yu et al. 2019). Meehl et al. (2018) also indicated that the decadal time scale variability in the tropical Atlantic likely contributed to the observed anomalously strong Arctic surface winds and sea ice drifts in summer after 2000. It is noticed that the spatial pattern of composite sea ice anomalies during the positive AMO phase (except for Baffin Bay and the Kara Sea) is similar to the regression pattern of sea ice on the Arctic sea ice PC2 (Fig. 4f).

Therefore, AMO has both dynamical and thermodynamical impacts on summer Arctic sea ice. During a positive AMO event, a remarkable warming occurs over the entire Arctic. At the same time, the anomalous meridional wind can effectively transport sea ice from the Pacific Arctic and central Arctic to the Atlantic Arctic, similar to DA forcing, and vice versa.

\section{4) COMposite AnAlysis BASED ON THE PDO}

The PDO index is also derived from SSTs, where the global mean has been removed. The negative phases of the PDO have 
(a) SLP

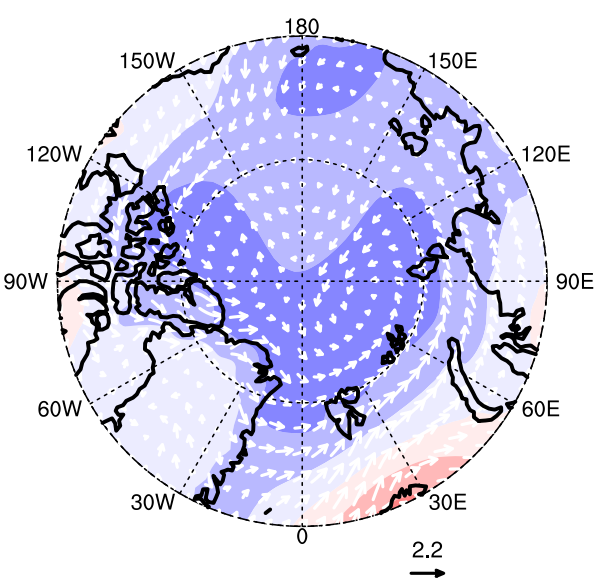

(c) SAT

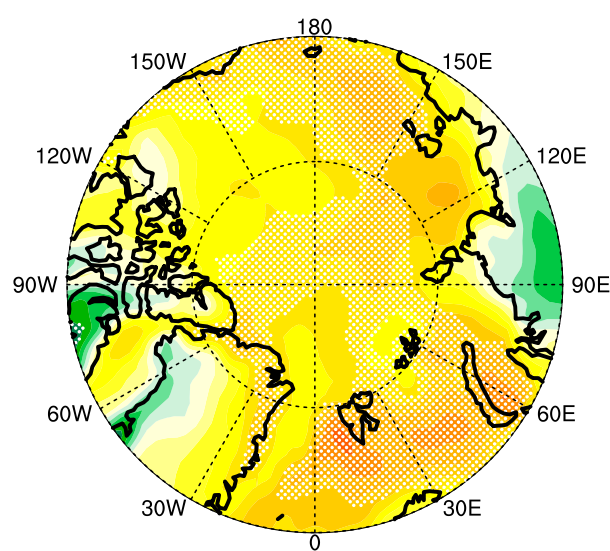

(e) SIA

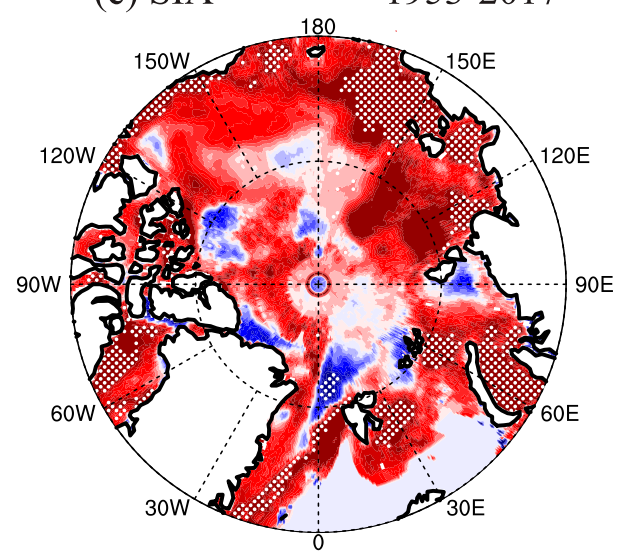

(b) SLP

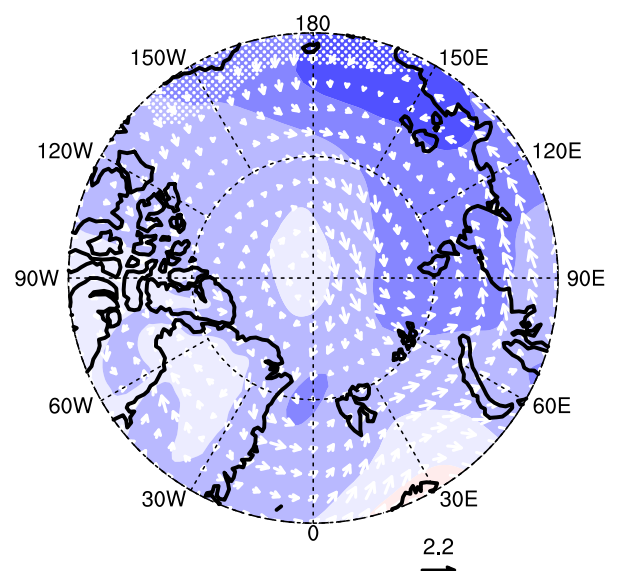

(d) SAT

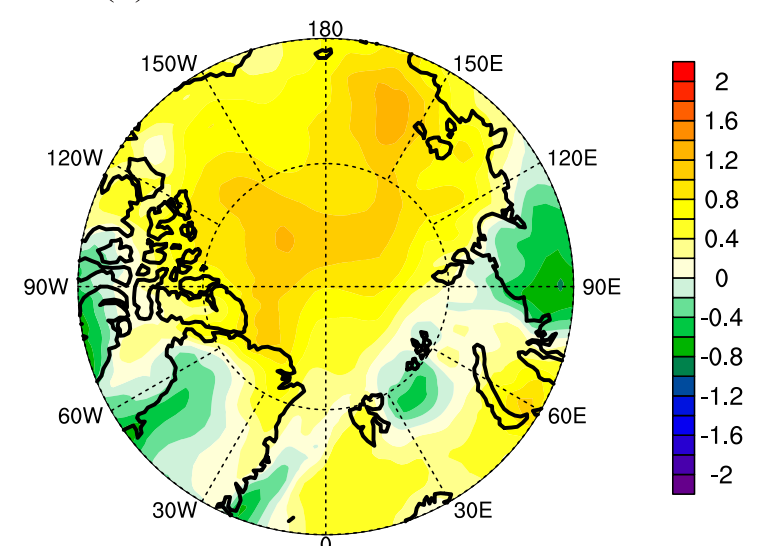

(f) SIA

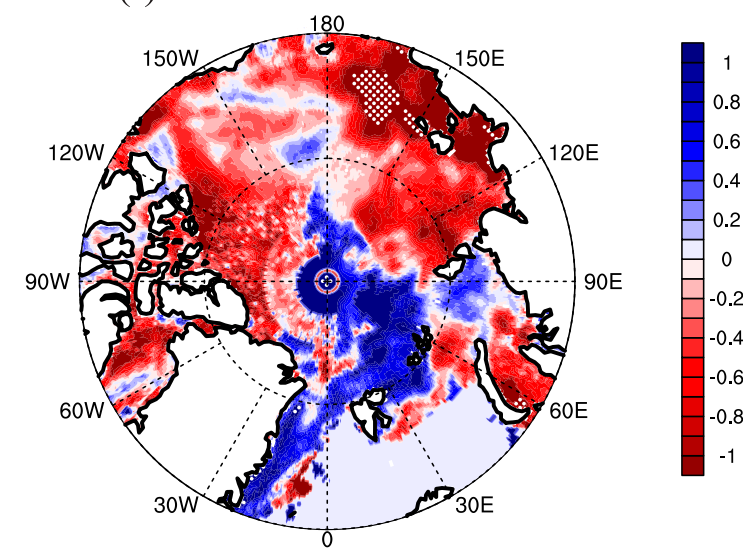

FIG. 7. The differences of composited (top) SLP and surface wind, (middle) SAT, and (bottom) SIA anomalies between positive winter NAO events and negative winter NAO events during (a),(c),(e) 1953-2017 and (b),(d),(f) 1979-2017. The regions above $95 \%$ confidence level are stippled.

been found to result in more rapid Arctic warming (Meehl et al. 2018; Screen and Francis 2016; McCrystall et al. 2020). During the positive (negative) PDO phase, with warm (cold) SST anomalies in the subtropical Pacific Ocean and the cold (warm) SST anomalies in the subpolar Pacific Ocean, SLP is below (above) average over the Arctic and above (below) average outside the Arctic region and midlatitudes (Yu et al. 2019; Figs. 9a-c). However, the period of 1900-52 shows some opposite features (Fig. 9a; the ERA-20C result is more reasonable in the composited SAT anomalies; not shown here). 
(a) SLP

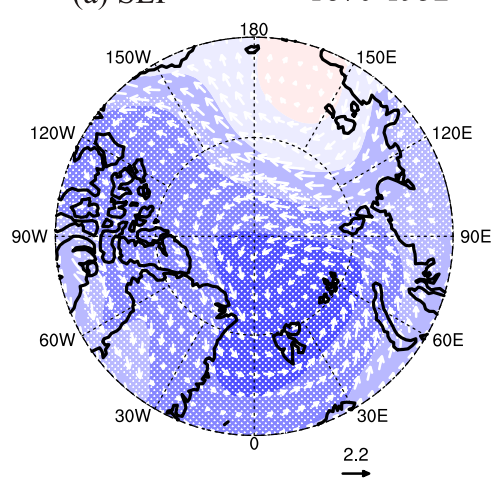

(d) SAT

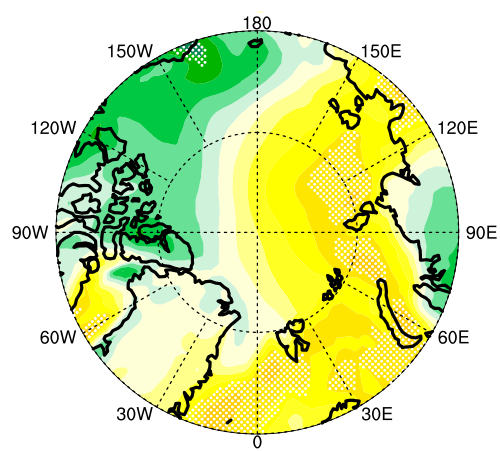

(g) SIA

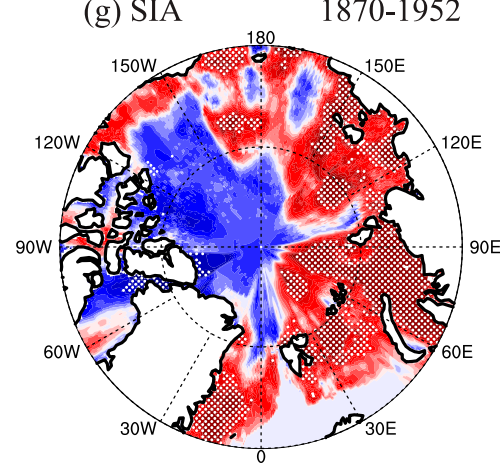

(b) SLP

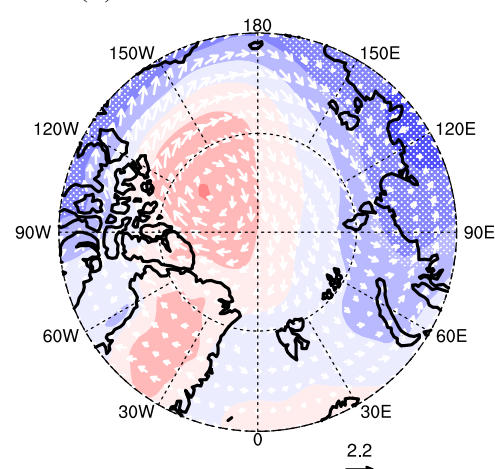

(e) SAT

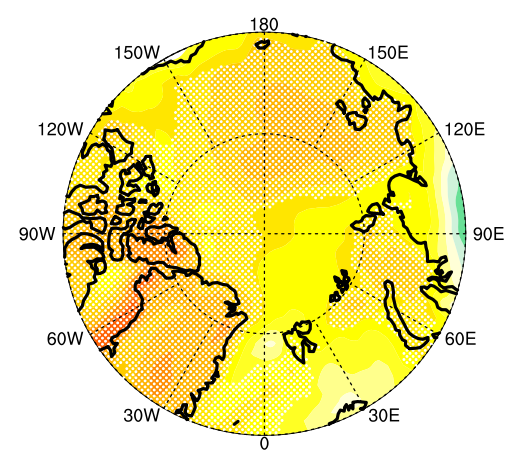

(h) SIA

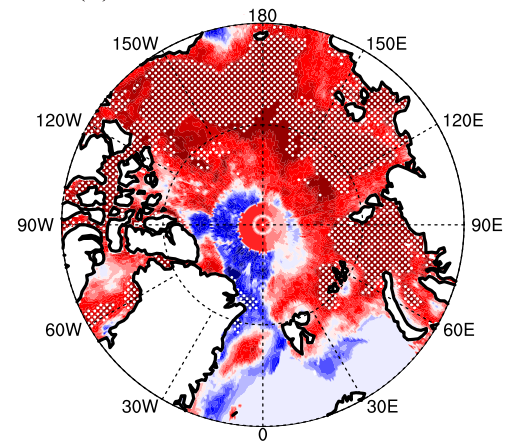

(c) SLP

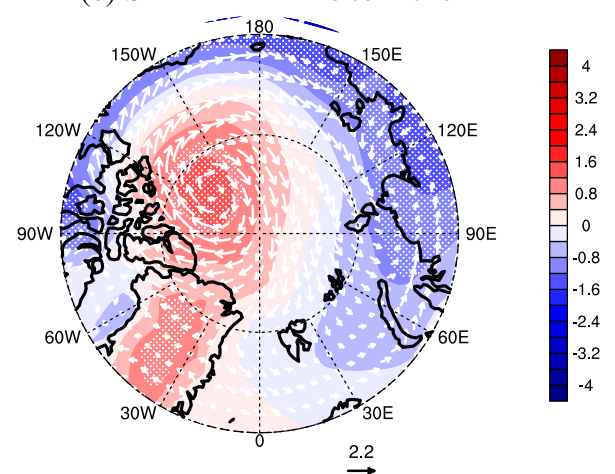

(f) SAT

1979-2015

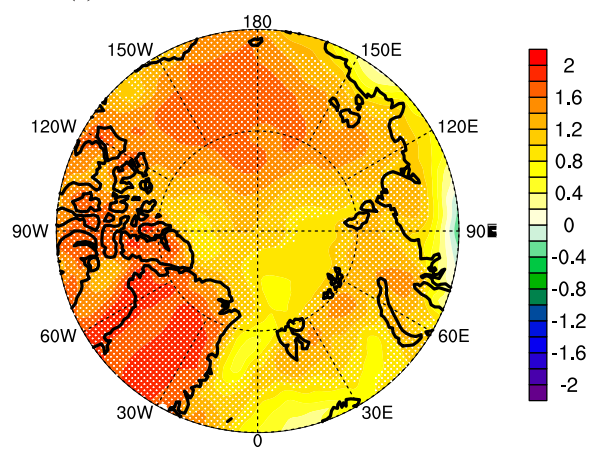

(i) SIA

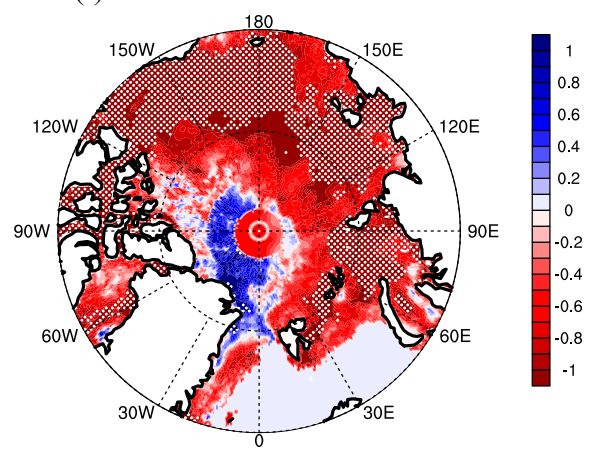

FIG. 8. The differences of composited (top) SLP and surface wind, (middle) SAT and (bottom) SIA anomalies between positive annual mean AMO events and negative annual mean AMO events during (a),(d),(g) 1870-1952, (b),(e),(h) 1953-2017, and (c),(f),(i) 1979-2017. The regions above $95 \%$ confidence level are stippled.

There were more negative events $(46.7 \%$ of the total events; Table 3) and the largest negative PDO events (2008, 2011, and 2012) happened during the period of 1979-2015. The more significant SAT and SLP anomalies also suggest that the negative PDO events became stronger in recent decades (Figs. 9c,f). It is noticed that this spatial pattern for the - PDO is similar to the regression pattern of SLP on the Arctic sea ice PC1 (Fig. 4a).

The positive (negative) PDO is related to more (less) SIA over the Arctic (Figs. 9h,i) due to the cooling (warming) effects (Figs. 9e,f) during both 1953-2015 and 1979-2015. However, the relatively strong anomalous meridional winds north of CAA and Greenland lead to strong advection of sea ice into the Fram Strait, resulting in reduction of sea ice in region north of CAA and Greenland. It is noticed that this spatial pattern of composite sea ice anomalies for the $-\mathrm{PDO}$ is similar to the regression pattern of sea ice on the Arctic sea ice PC1, especially during 1979-2017 because of the intensified SAT difference (Figs. 9i and 4e).

Based on the above analyses, the atmospheric circulation patterns, which drive ocean circulation and sea ice advection, also regulate the spatial distribution of sea ice. In addition, by affecting pan-Arctic climate with advected SAT, atmospheric circulation patterns play an important role in sea ice change to the entire Arctic Ocean (Wang et al. 2005).

\section{5) COMPOSITE ANALYSIS OF SEA ICE THICKNESS AND ADVECTION FROM PIOMAS}

To independently confirm the validity of the results using SIA, we used the PIOMAS-simulated sea ice thickness (SIT) 
(a) SLP

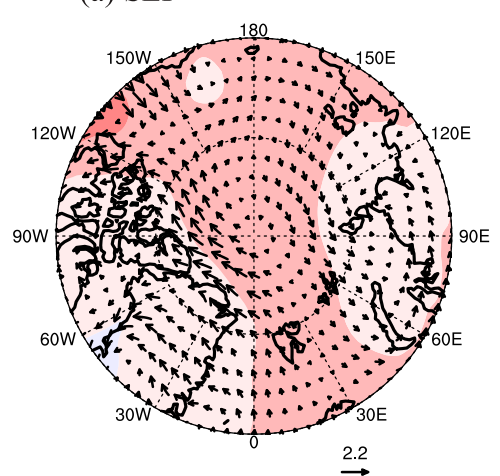

(d) SAT

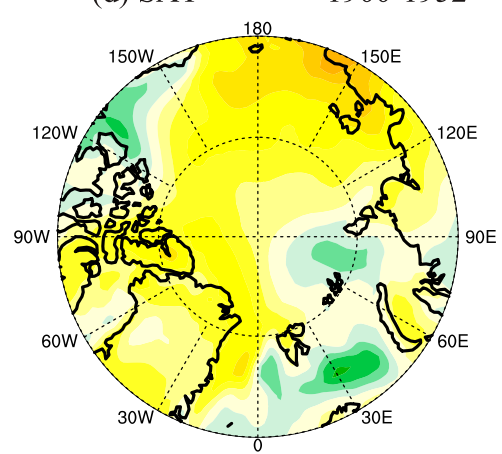

(g) SIA

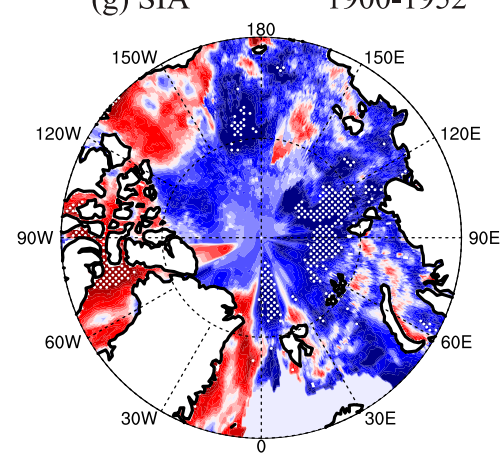

(b) SLP

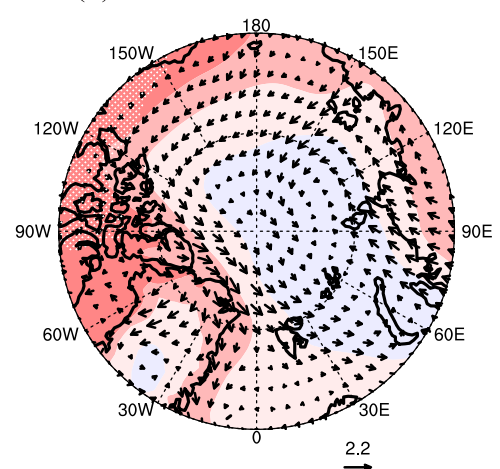

(e) SAT

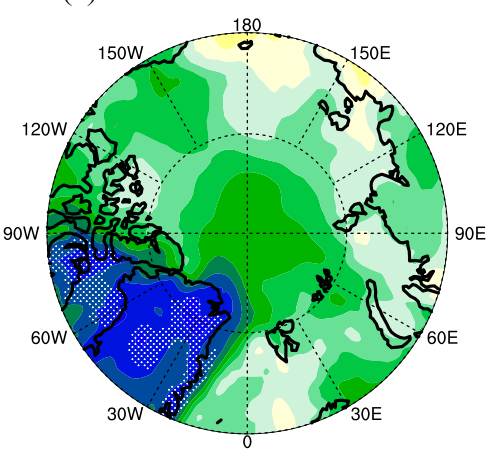

(h) SIA

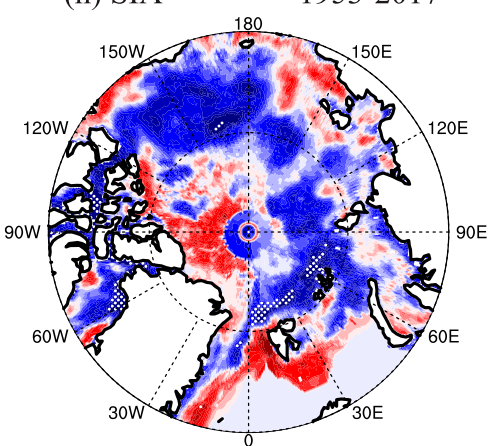

(c) SLP

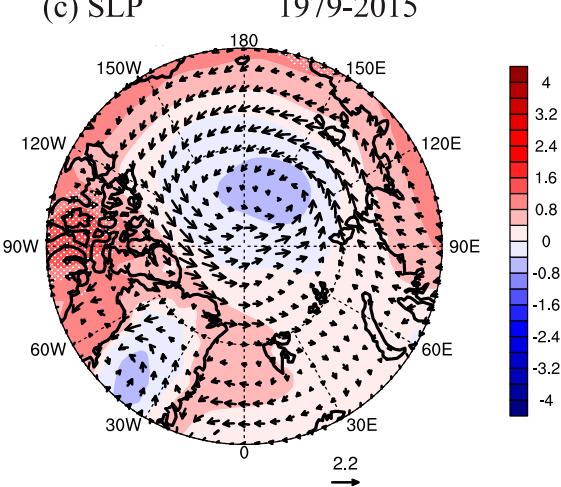

(f) SAT

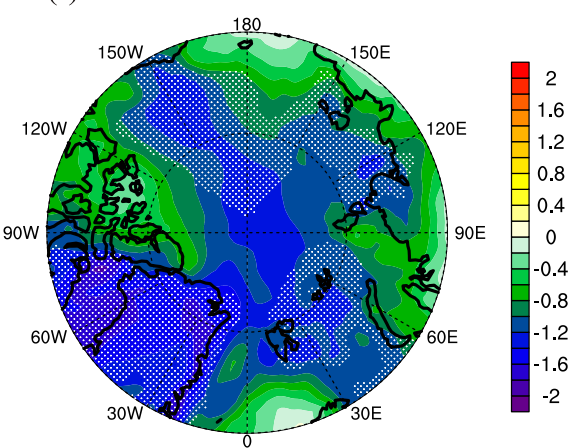

(i) SIA

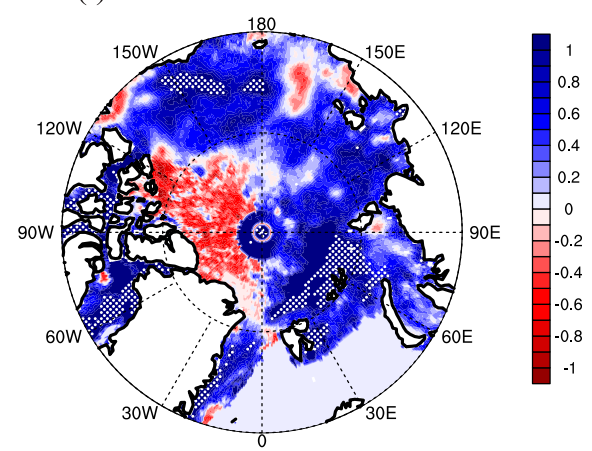

FIG. 9. The differences of composited (top) SLP and surface wind, (middle) SAT, and (bottom) SIA anomalies between positive summer PDO events and negative summer PDO events during (a),(d),(g) 1900-52, (b),(e),(h) 1953-2017, and (c),(f),(i) 1979-2017. The regions above $95 \%$ confidence level are stippled.

and velocity output for the period 1978-2017 (Zhang et al. 2008 ) to conduct a similar composite analysis. Figure $10 \mathrm{f}$ shows the average (1978-2017) ice thickness and flow distribution. Old, thick ice exists along the margin of the North American and Greenland Arctic Basins, which is attributed to sea ice motion associated with the anticyclonic Beaufort Gyre and the transpolar drift stream (Bourke and Garrett 1987; Fig. 10f).

Summer SIT difference between the positive and negative AO phase (Fig. 10a) shows an increase due to its anomalous divergence or cyclonic circulation (convergence or anticyclonic circulation) for its positive (negative) phase and cooling during positive AO (see Fig. 5j). This indicates that the spread or divergence of ice cover promotes ice growth, because the ice thickness is low. Similarly to the ice concentration, sea ice thickness differences between the positive and negative phases of the DA (Fig. 10b) and AMO (Fig. 10d) show a decrease because 1) the anomalous strong TDS and meridional sea ice flow driven by the meridional winds, which are derived from +DA (Fig. 6c) and + AMO (Fig. 8c), effectively advect sea ice out of the Arctic (Wang et al. 2009, 2014) and 2) sea ice melts faster due to anomalous warming produced by the $+\mathrm{DA}$ (see Fig. 6f) and + AMO (see Fig. 8f).

The composite SIT difference map between the winter $+\mathrm{NAO}$ and -NAO phase shows an increase of SIT in the western central Arctic and a decrease in the eastern Arctic. The intensification of the cyclonic circulation in the eastern Arctic Ocean (Fig. 7b) leads to anomalous strong sea ice flows originated along the coasts of the East Siberian, Laptev, and Kara 
(a) $\mathrm{AO}$

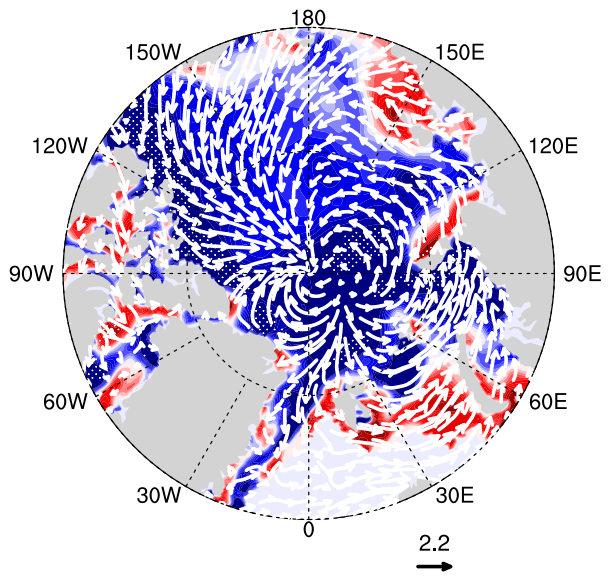

(c) NAO

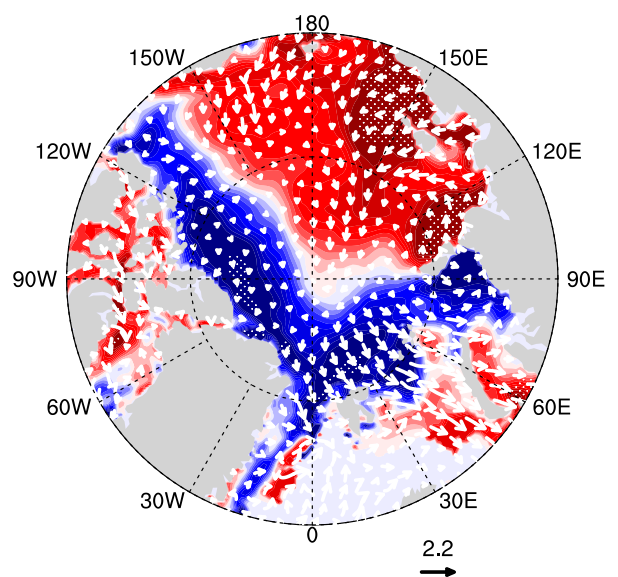

(e) PDO
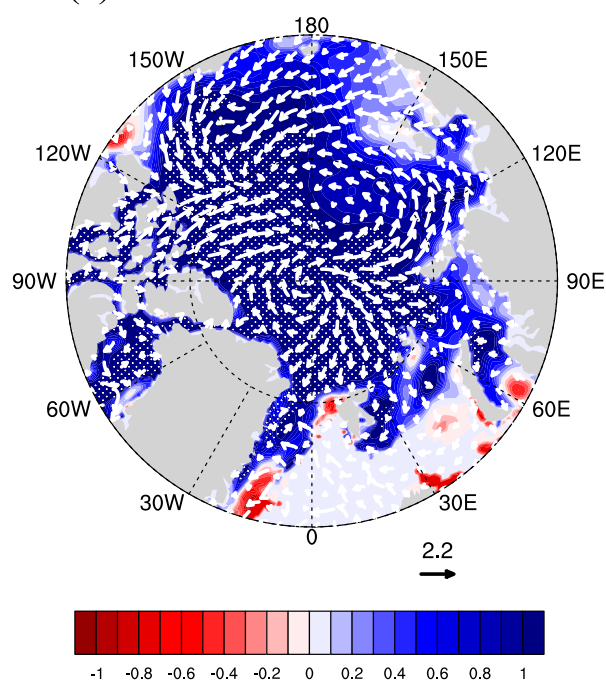

(b) $\mathrm{DA}$

$1979-2015$

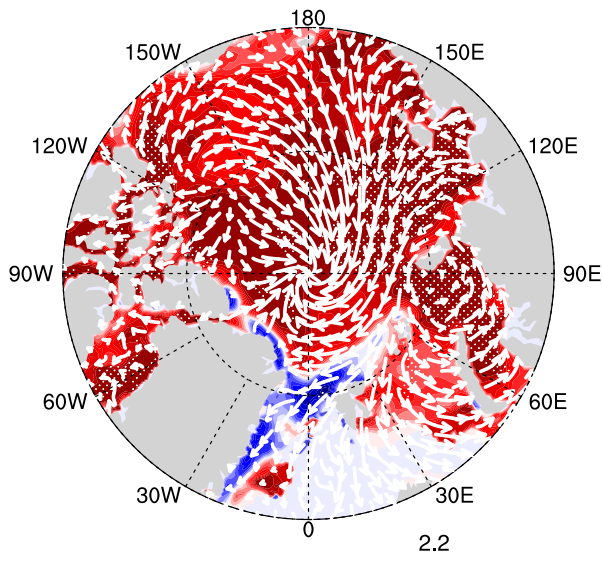

(d) AMO

1979-2017

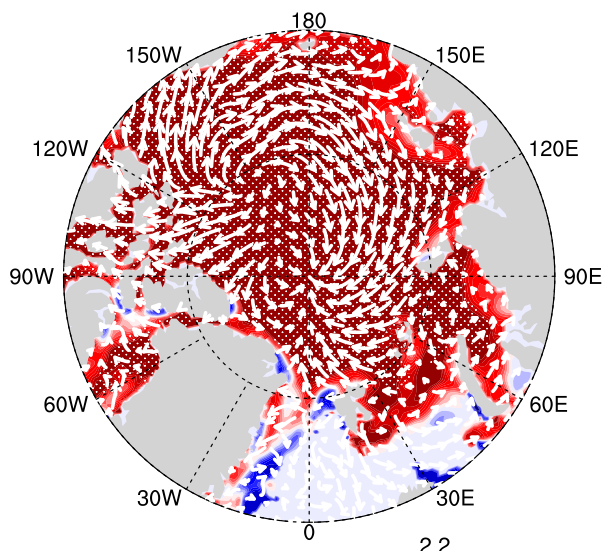

$\stackrel{2.2}{\longrightarrow}$

(f) summer mean

1979-2017
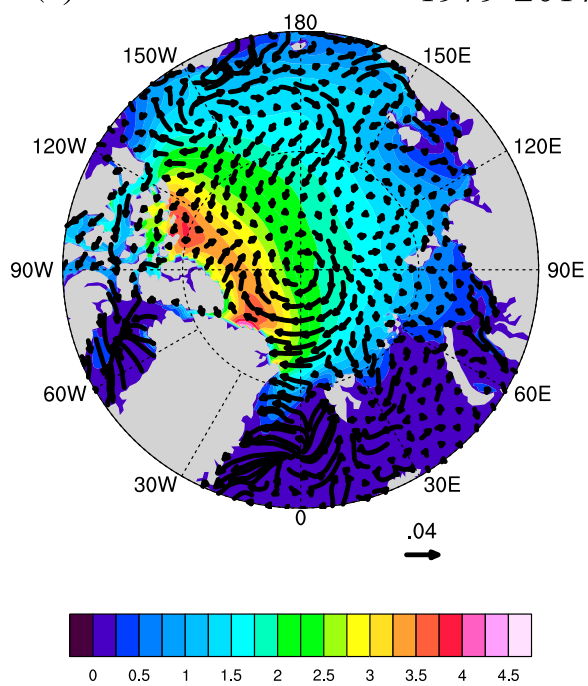

FIG. 10. PIOMAS-simulated summer SIT (shading) and motion (vector) composite differences between positive and negative (a) summer AO during 1979-2015, (b) summer DA during 1979-2015, (c) winter NAO during 1979-2017, (d) annual mean AMO during 1978-2017, and (e) summer PDO during 1978-2017 and (f) the climatological mean of SIT (shading; $\mathrm{m}$ ) and motion (vector; $\mathrm{m} \mathrm{s}^{-1}$ ) for 1979-2017. The regions above $95 \%$ confidence level are stippled. The sea ice velocity vector scale (2.2) in (a)-(e) is normalized ice speed with no unit, while in (f) it is $0.04 \mathrm{~m} \mathrm{~s}^{-1}$. 
Seas, which merge into the TDS, and exit to the Atlantic Arctic. The increase of SIT north of CAA and Greenland indicates that the associated cyclonic surface wind anomalies in the eastern Arctic Ocean (Fig. 7b) cause the divergence of existing sea ice to the western central Arctic. However, the increase in SIT in the western Arctic (Fig. 10c) differs from the decrease in SIA north of CAA and Greenland (see Fig. 7f). This is consistent with the results of Schweiger et al. (2011) that the largest differences in ice thickness patterns occur in a narrow band along the northern coast of Greenland and Canadian Archipelago and the ice thickness in the Beaufort and Chukchi Seas is somewhat thinner than the observations. It could be due to the fact that PIOMAS seems to have difficulties reproducing the thick ice along the coast under the current configuration with smooth, low-resolution forcing fields (Schweiger et al. 2011).

The composite SIT difference map between the + PDO and -PDO (Fig. 10e) indicates a significant increase of ice thickness as a result of cooling in the entire Arctic (see Fig. 9f) and its anomalous cyclonic (divergence) ice flow (Fig. 10e), consistent with the increase in ice concentration (Fig. 9i).

Overall, the distributions of SIT anomalies are similar to those of SIA anomalies (Figs. 10a-e), indicating that the variability of the atmospheric circulation would not only lead to abnormal sea ice advection and TDS (SIA anomaly) due to the strengthening or weakening of wind forcing, but also promote some feedback processes (e.g., a positive feedback mechanism of sea ice albedo); thus, it also causes the variabilities of SIT (Rigor et al. 2002; Skeie 2000; Wu et al. 2006; Moore et al. 2019).

\section{6) Correlation Between SUMmer SIA AND DOMINANT INTERNAL VARIABILITIES OF THE CLIMATE SYSTEM}

Table 5 shows the correlation coefficients between the summer Arctic sea ice PCs and each dominant atmospheric pattern index during the three periods. Each index is detrended. PC1 is well related with the Arctic SAT, AO, DA, NAO, and AMO, in which Arctic SAT and AMO are statistically significant at the $95 \%$ level. It indicates that the reduction of SIA in the whole Arctic is primarily driven by atmospheric temperature fluctuations (Sedlar and Tjernström 2017; Olonscheck et al. 2019), which are associated with both the climate anthropogenic warming and the warming caused by dominant atmospheric patterns (positive DA, NAO, and $\mathrm{AMO}$ and negative $\mathrm{AO}$ and PDO). As AMO and PDO have been separated from any "global warming" signal, the link between in-phase sea ice variability and atmospheric temperature fluctuations induced by AMO and PDO is largely independent of anthropogenic forcing.

The correlation between PC2 and Arctic SAT is weak during the three periods. DA shows consistent relationship with coefficients of 0.14, 0.18, and 0.20 for 1850-1952, 1953-2015, and 1979-2015, respectively. PC2 has a statistically significant relationship with NAO during 1979-2017. Correspondingly, more positive NAO events, including the strongest events, occurred in this period of time. Better correlation with the AMO (PDO) is only shown in 1870-1952 (1900-52). The regression and composite analyses (Figs. 4-9) suggest that the 
mechanisms involved in PC2 are rather complicated. Partly, the dynamical forcing from each dominant atmospheric pattern is the major driver of the observed out-of-phase sea ice variabilities between the Pacific Arctic and Atlantic Arctic, especially the anomalous transpolar wind/ice drift due to DA and AMO's strong meridionality. The thermodynamical forcing is of minor relevance for the mode 2 of summer sea ice variability. However, both dynamical and thermodynamical forcings from dominant modes of climate variability are unable to completely explain the sea ice variation.

During the recent decades, the correlation between PC1 and AO/NAO became larger, which may be associated with the stronger AO and NAO events during 1979-2017 (Table 3). However, PC2 shows smaller correlation with AO and has a stronger relationship with NAO and AMO during 1979-2017.

7) Multiple LinEAR REGRESSION BETWEEN SEA ICE PCS AND DOMINANT MODES OF CLIMATE VARIABILITY

The impacts of the individual teleconnection pattern on changes in SIA and their correlations have been explored above. To explore the functional relationships statistically, the multiple linear regression is used in this section. However, the disadvantages of multiple linear regression are that it is not possible to disentangle the complex interactions between each internal climate variability (AO, DA, NAO, AMO, PDO) and external forcings (e.g., anthropogenic aerosol and greenhouse gases), and the contributions of external forcings could not be expressed explicitly in the regression models. Therefore, each component of internal climate variability (AO, DA, NAO, AMO, PDO) is only shown in the following regression models for sea ice variability.

The regression models for sea ice PC1 are only shown for 1953-2017 and 1979-2017. Training the 1953-2017 data, we obtain

$$
\begin{aligned}
\hat{Y}_{\mathrm{PC} 1}= & -0.046-0.31 \mathrm{AO}+0.23 \mathrm{DA}+0.42 \mathrm{NAO} \\
& +0.49 \mathrm{AMO}-0.25 \mathrm{PDO} .
\end{aligned}
$$

The coefficient of multiple determination $\left(R^{2}\right)$ is 0.46 and is statistically significant at the $95 \%$ level, indicating nearly onehalf of the variability is due to the internal climate variability regardless of external forcings (e.g., anthropogenic aerosol and greenhouse gases). For 1979-2017, the following equation is derived:

$$
\begin{aligned}
\hat{Y}_{\mathrm{PCI}}= & -0.016-0.40 \mathrm{AO}+0.22 \mathrm{DA}+0.49 \mathrm{NAO} \\
& +0.25 \mathrm{AMO}-0.24 \mathrm{PDO}
\end{aligned}
$$

and $R^{2}$ decreased to 0.28 .

Combining the standardized partial regression coefficients ( $b_{i}^{\prime}$ in Table 6), the AMO, NAO, AO, PDO, and DA all statistically contribute significantly to the in-phase fluctuation of SIA in the whole Arctic (except for the Greenland Sea), of which the most important is the AMO during 1953-2017. For the recent decades, the NAO and AO seem to play a more important role, which is consistent with the correlation results in Table 5.
For the dipolar pattern with out-of-phase variabilities between the Pacific Arctic and the Atlantic Arctic during 19532017, the trained model for PC2 is given by

$$
\begin{aligned}
\hat{Y}_{\mathrm{PC} 2}= & -0.010-0.28 \mathrm{AO}+0.19 \mathrm{DA}+0.16 \mathrm{NAO} \\
& +0.14 \mathrm{AMO}+0.052 \mathrm{PDO} .
\end{aligned}
$$

Only the AO shows a significant contribution to $\mathrm{PC} 2$ $\left(b_{i}^{\prime}=-0.28\right)$; DA is the second $\left(b_{i}^{\prime}=0.19\right)$, and PDO is the least $\left(b_{i}^{\prime}=0.05\right.$; Table 6$)$. However, $R^{2}$ for the regression model is only 0.11 .

For the period of 1979-2017, the trained model is

$$
\begin{aligned}
\hat{Y}_{\mathrm{PC} 2}= & 0.015-0.16 \mathrm{AO}+0.19 \mathrm{DA}+0.56 \mathrm{NAO} \\
& +0.55 \mathrm{AMO}+0.15 \mathrm{PDO} .
\end{aligned}
$$

Since 1979, the effects of NAO and AMO increased $\left(b_{i}^{\prime}=0.54\right.$ and 0.42 , respectively), followed by DA $\left(b_{i}^{\prime}=0.17\right)$, and $R^{2}$ is 0.30 , reaching statistical significance at the $95 \%$ level, indicating that $30 \%$ of sea ice variability of PC2 (mainly dynamical effect) is explained by the internal climate variability during 1979-2017.

In summary, regardless of external forcings (e.g., anthropogenic aerosol and greenhouse gases), the internal climate variability explained $46 \%$ of $\mathrm{PC} 1$ and $11 \%$ of PC2 during $1953-$ 2017, and explained $28 \%$ of PC1 and $30 \%$ of PC2 during 19792017. Therefore, the internal climate variability accounts for $57 \%$ of total sea ice variability (PC1 and PC2 combined) during 1953-2017, and 58\% during 1979-2017. Nevertheless, the variability of PC1 (thermodynamical effect) decreased from $46 \%$ during $1953-2017$ to $28 \%$ during 1979-2017, while the variability of PC2 (dynamical effect) increased from $11 \%$ during 1953-2017 to 30\% during 1979-2017. This implies that as Arctic summer sea ice is diminishing, the wind forcing (dynamical effect) plays an enhanced role in sea ice advection, because the thinning summer sea ice is more vulnerable to wind forcing (Spreen et al. 2011; Zhang et al. 2012).

Although the statistical contributions of external forcings (e.g., anthropogenic aerosol and greenhouse gases) could not be unveiled in the regression models, our results (up to $46 \%$ of PC1 and up to $30 \%$ of PC2 are explained by the internal climate variability) are consistent with the previous studies. Using ensemble model runs, Ding et al. (2019) estimated that $40 \%-50 \%$ of ice variability is attributed to internal climate variability. Olonscheck et al. (2019) concluded that atmospheric temperature fluctuation (thermodynamical forcing) dominates the sea ice loss, while other drivers (wind forcing) contribute $25 \%$ of ice variability (a dynamical effect). Zhang et al. (2008) estimated, using PIOMAS, that about $70 \%(30 \%)$ of sea ice loss in the Pacific Arctic is due to thermodynamical (dynamical) effects.

Note that the $70 \%$ of sea ice PC1 (thermodynamical effect) variability includes the external forcing, internal climate variability (from 46\% during 1953-2017 to 28\% during 1979-2017), and the interactions among each internal climate variability. The reason is that the PC1 is partially a forced response to the anthropogenic warming, as discussed in section $3 \mathrm{~d}$ using the multiple large ensembles of climate simulations and singleforcing ensembles. 
TABLE 6. Standardized partial regression coefficients for the multiple linear regression model between summer Arctic sea ice PC1/PC2 and summer AO, summer DA, winter NAO, annual mean AMO, and summer PDO during different periods (the $95 \%$ significance levels in bold are determined by an $F$ test).

\begin{tabular}{|c|c|c|c|c|}
\hline \multirow[b]{2}{*}{$\hat{Y}(\mathrm{AO}, \mathrm{DA}, \mathrm{NAO}, \mathrm{AMO}, \mathrm{PDO})$} & \multicolumn{2}{|c|}{ Regression model for PC1: $b_{i}^{\prime}$} & \multicolumn{2}{|c|}{ Regression model for PC2: $b_{i}^{\prime}$} \\
\hline & $1953-2017$ & 1979-2017 & 1953-2017 & 1979-2017 \\
\hline $\mathrm{AO}$ & -0.31 & -0.39 & -0.28 & -0.16 \\
\hline DA & 0.22 & 0.19 & 0.19 & 0.17 \\
\hline NAO & 0.40 & 0.48 & 0.14 & 0.54 \\
\hline AMO & $\mathbf{0 . 5 0}$ & 0.19 & 0.13 & 0.42 \\
\hline PDO & -0.25 & -0.21 & 0.05 & 0.13 \\
\hline
\end{tabular}

\section{c. Mechanisms accelerating decline in Arctic summer sea ice: A positive ice-ocean albedo feedback loop}

Based on the investigation conducted in this paper and previous studies (Wang et al. 2005, 2014), the accelerated decline of Arctic summer sea ice can be summarized using the proposed feedback loop shown in Fig. 11). This updated feedback loop can explain both atmospheric dynamical and thermodynamical forcings, which contribute to the unprecedented decline of Arctic summer sea ice. The existing annual ice-ocean albedo feedback loop (shown in the dotted boarded rectangle in Fig. 11) is the ice-ocean albedo feedback in response to the increase in SST and SAT, resulting in enhanced sea ice melting, as described by Wang et al. $(2005,2014)$.

Global warming is an anthropogenic effect (Min et al. 2008; England 2021), which can directly speed up the existing iceocean albedo feedback. In our work, we emphasized the thermodynamical forcing exerted from the internal variabilities of climate system. During the $-\mathrm{AO},+\mathrm{NAO},+\mathrm{DA},+\mathrm{AMO}$, and - PDO, Arctic SAT experienced positive anomalies. It is noticed that during the recent decades, DA, NAO, and AMO showed more warming phases (Figs. 6-8), indicating that they simultaneously contributed to the Arctic amplification (i.e., increased Arctic SAT and SST), which accelerated the positive ice-ocean albedo or ice-SAT feedback loop, leading to unprecedented decline of summer Arctic sea ice.

At present, such feedback is mainly reflected in the peripheral seas of the Arctic Ocean, but with the farther northward expansion of the marginal ice zone in summer (e.g., Strong and Rigor 2013) these feedback processes will also be reflected in the central Arctic region in the near future.

Besides the thermodynamical effect, these dominant internal climate modes also produce a dynamical effect by directly causing anomalous atmospheric circulation and driving anomalous ocean circulation over the pan Arctic (Wang et al. 2005). More specifically, the anomalous meridional winds induced by positive DA and positive AMO (Figs. 6a-c and 8b,c) would effectively transport sea ice from the Pacific Arctic and central Arctic to the Atlantic Arctic along with the downstream TDS (Wang et al. 2009, 2014). Based on the positive ice-ocean albedo feedback, the SIA decline could be accelerated, especially in the Pacific Arctic.

The opposite signs of the modes would slow down the iceocean albedo feedback, reflecting their competitive impacts. The feedback loop exists all the time as long as there are openings (seasonal ice) in the Arctic. In fact, this ice-ocean feedback loop (a subloop) is embedded in a decadal Arctic atmosphere-ice-ocean-climate (dynamical and thermodynamical) cycle, as shown in Fig. 13 of Wang et al. (2005). Considering the sea ice outflow along TDS, it is easier for the Pacific Arctic to lose sea ice than to gain sea ice during positive AO, DA, NAO, and AMO. As a consequence, the positive ice-ocean albedo feedback loop is easier to be accelerated than to be slowed down in the Pacific Arctic. To reverse the positive to negative feedback, the Arctic needs a sudden extreme cooling (which may be possible if all the internal modes or teleconnection patterns produce an extreme cooling at the same time) to overcome the present warming trend and dynamically strong anomalous persistent winds against TDS prevail (which can retain sea ice in the Pacific Arctic).

Therefore, the accelerated decline of SIA in recent decades is not uniquely driven by a single factor, but rather by a combination of global warming and AO, DA, NAO, AMO, and

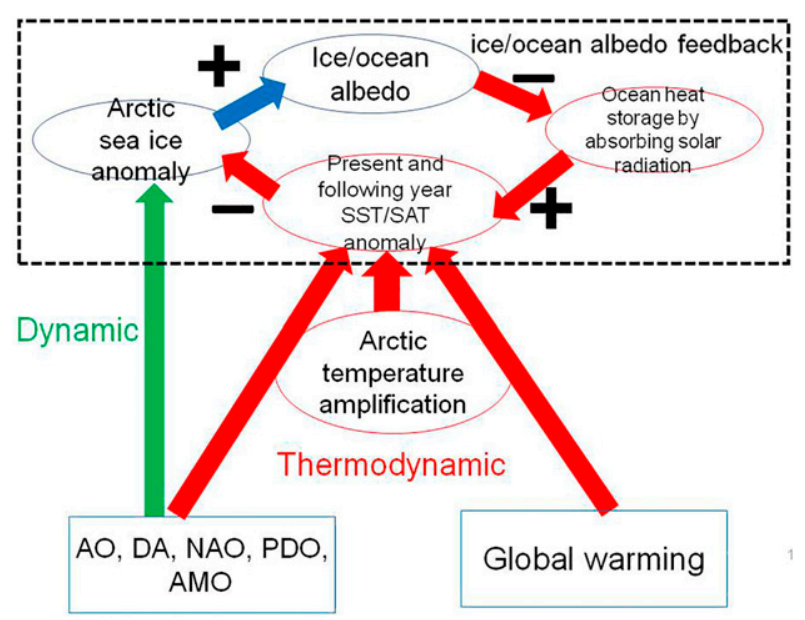

FIG. 11. An ice-ocean albedo feedback loop is accelerated by both the global warming and the dominant internal variabilities of climate system forcing. The red arrows are associated with thermodynamic processes. The green arrow is associated with dynamic processes. The plus $(+)$ and minus $(-)$ signs denote the positive and negative feedback, respectively. An arrow with a plus sign between box A and box B means that a positive (negative) anomaly in A would cause a positive (negative) anomaly in B after a certain delay, while an arrow with a minus sign would result in a negative (positive) anomaly in B. 


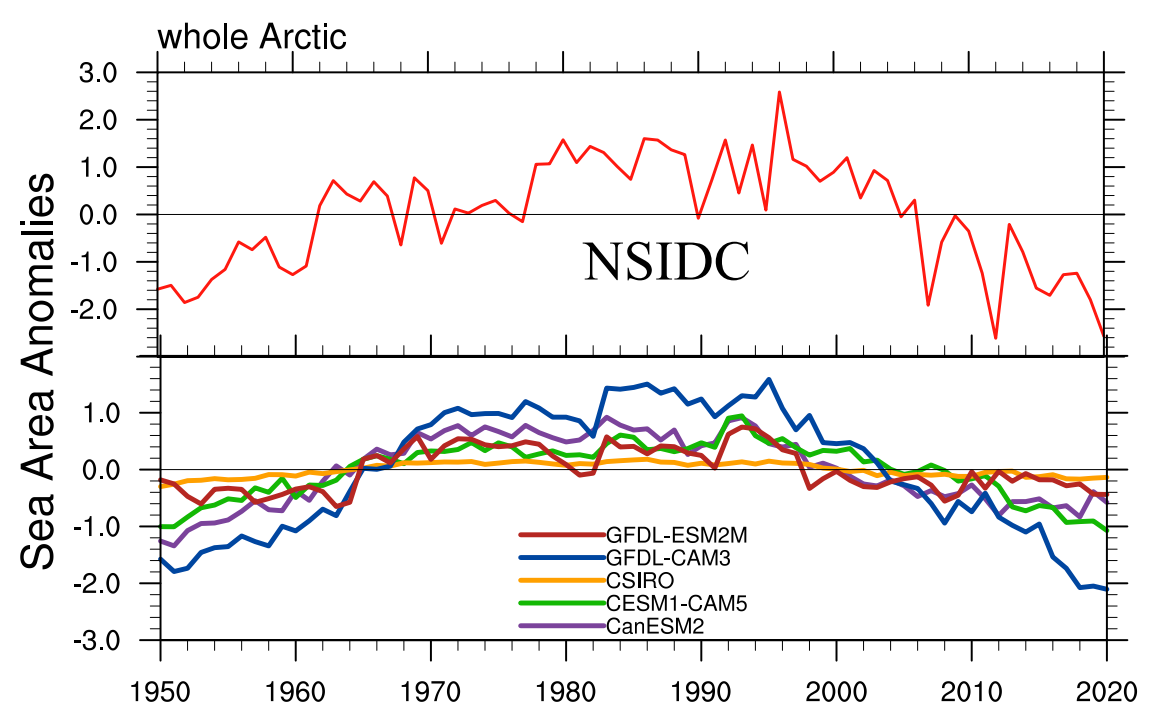

FIG. 12. The observed (NSIDC) and ensemble mean summer (June-September) SIA anomalies (detrended for 1950-2020) in each model (Table 1) over the whole Arctic $\left(10^{6} \mathrm{~km}^{2}\right)$.

PDO through both thermodynamical and dynamical processes (Zhang et al. 2008; Wang et al. 2014).

\section{d. Discussion: Is the multidecadal oscillation of sea ice a forced response?}

Some studies have shown the multidecadal oscillation in sea ice (Wang and Ikeda 2001; Ikeda et al. 2001; Wang et al. 2005). Nevertheless, a question of whether or not the oscillation is a forced response to anthropogenic emissions or part of internal climate variability is poorly understood. England (2021) examined the multidecadal fluctuations of Arctic surface temperature and indicated that the multidecadal fluctuations in Arctic surface temperature about a linear trend are a response to anthropogenic forcing and not internal variability (see his Figs. S1a,b). This has obvious implications for the multidecadal fluctuations of Arctic sea ice about a linear trend, because the fluctuations in Arctic surface temperature are extremely similar to PC1 of sea ice (Fig. 3f).

We further investigate the nature of the multidecadal oscillation using the same multiple large ensembles of climate simulations (Table 1) and single-forcing ensembles (Table 2) used by England (2021). The observed (NSIDC) and ensemble means of summer (June-September mean) SIA anomalies (detrended for 1950-2020) over the whole Arctic are shown in Fig. 12. The large ensembles simulations replicate the longterm Arctic sea ice oscillation about the linear trend in most Arctic regions. Therefore, the multidecadal oscillation in Arctic summer sea ice can be explained as a forced response to anthropogenic emissions. Furthermore, based on the singleforcing ensembles (Table 2), the ensemble mean summer SIA response, relative to 1920 in CESM1-CAM5, is shown in Fig. 13. After removing a linear trend, anthropogenic aerosols and greenhouse gases can explain the observed multidecadal Arctic sea ice anomalies in the Arctic Ocean.

In summary, this study focuses on the contributions from internal variability of the teleconnection patterns (AO, DA,
NAO, AMO, PDO) to the interannual and decadal variability of summer Arctic sea ice. Using statistical methods alone, it is not possible to disentangle the complex interactions between each internal climate variability (AO, NAO, AMO, PDO) and external forcings (e.g., anthropogenic aerosol and greenhouse gases).

\section{Conclusions and discussion}

This study analyzes the interannual and decadal variability of summer sea ice over six Arctic regions using the longest gridded sea ice data (1850-2017) and reveals the relationships with the dominant internal variabilities of the climate system (i.e., the teleconnection patterns). The major findings are summarized below.

1) The composite analysis illustrates the typical distribution of the atmospheric circulation anomalies, SAT, and SIA for the major internal variabilities of the climate system. During the $-\mathrm{AO}$, +NAO, +DA, + AMO, and - PDO, Arctic SAT (SIA and SIT) experienced positive (negative) anomalies, and vice versa during the opposite phases. However, DA- and AMO-derived wind anomalies are meridional, while wind anomalies derived from AO, NAO, and PDO are more zonal in nature.

2) The leading EOF mode of summer Arctic sea ice exhibits in-phase fluctuation, and with more significant positive events since 1979, the reduction of SIA was accelerated. The multiple linear regression analysis shows that $46 \%$ of ice reduction $(\mathrm{PC} 1)$ is due to $\mathrm{AMO}, \mathrm{NAO}, \mathrm{AO}, \mathrm{PDO}$, and DA. The global warming and the warmings caused by positive AMO, positive NAO, negative AO, negative PDO, and positive DA simultaneously play a key role in driving this variability. Although the statistical contributions of external forcings (e.g., anthropogenic aerosol and greenhouse gases) could not be unveiled in the regression models, 


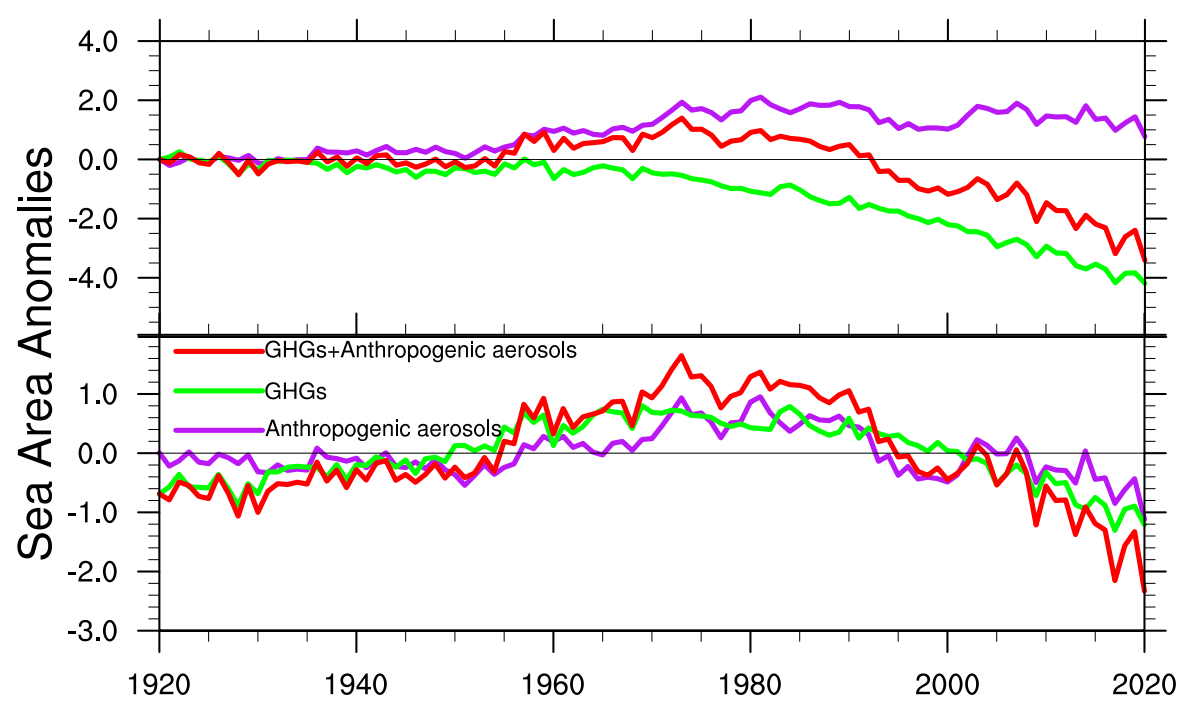

FIG. 13. (top) The ensemble mean summer SIA response $\left(10^{6} \mathrm{~km}^{2}\right)$ relative to 1920 in CESM1CAM5 to anthropogenic aerosols (historical run - xaer run; purple), greenhouse gases (historical run - xghg run; green), and both anthropogenic aerosols and greenhouse gases $(2 \times$ historical run - xaer run - xghg run; red) over the whole Arctic Ocean. (bottom) The linearly detrended counterpart of the top row.

our result is consistent with other studies; for example, using ensemble model runs, Ding et al. (2019) showed that $40 \%-50 \%$ of sea ice variability is explained by internal climate variability, and Olonscheck et al. (2019) found that atmospheric temperature fluctuation is the dominant forcing in sea ice loss. England et al. (2019) and others demonstrated that internal variability has had a significant and spatially complex impact on recent historical Arctic sea ice loss $(30 \%-50 \%)$; however, the observational estimates of the sensitivity of Arctic sea ice to emissions and global temperature are associated with large uncertainties.

3) The second EOF mode of summer Arctic sea ice captures a dipolar pattern with out-of-phase variabilities between the Pacific Arctic and the Atlantic Arctic. Although there are no external forcings (e.g., anthropogenic aerosol and greenhouse gases) explicitly expressed in the multiple linear regression, with the greater importance of the NAO and AMO, the dominant modes of climate variability can explain up to $30 \%$ of the total variance. For this mode, the dynamical forcing induced by DA and AMO's strong meridional wind is more significant than the thermodynamical forcing. Our result is consistent with Olonscheck et al.'s (2019) finding that other drivers (wind forcing etc., excluding temperature fluctuation) explain $25 \%$ of sea ice variability.

4) The ETCW effect was captured by both the leading and second EOF modes of summer sea ice with a decrease in SIA. This indicates that the Arctic-wide sea ice reduction represented by $\mathrm{PC1}$ was the consequence of the ETCW. During the same period, dynamical advection of sea ice out of the Arctic by the meridional wind forcing represented by PC2 also contributed to the reduction of the Arctic summer sea ice during ETCW.
5) Under the Arctic amplification, attributed to the increasingly intensified atmospheric thermodynamical forcing of each dominant atmospheric pattern (more and stronger events occurred; Table 3) and DA- and AMO-associated strong meridional wind forcing, the sea ice retreat in the Arctic has been accelerated in the recent decades due to accelerating positive ice-ocean albedo feedback, as summarized by Fig. 11.

6) Using ensemble runs of several climate models, it is confirmed that similar to fluctuations in Arctic surface temperature (England 2021), the in-phase, multidecadal oscillations (i.e., mode 1) in Arctic summer sea ice (Wang and Ikeda 2001; Wang et al. 2005) are partially a forced response to anthropogenic emissions of aerosols and greenhouse gasses.

Based on the EOF analysis of summer sea ice over six Arctic regions, we conclude that besides the external forcing (e.g., anthropogenic aerosol and greenhouse gases; England 2021), the dominant modes of the internal climate variabilities play an important role in the Arctic amplification (Wettstein and Deser 2014; Zhang 2015; Ding et al. 2017, 2019), because the atmospheric dynamical and, especially, thermodynamical processes enhance the existing Arctic warming that speeds up the positive ice-ocean albedo feedback loop. As a result, summer sea ice decline in the Arctic has been accelerated during the recent decades.

To demonstrate the strong coupling between the EOF modes of Arctic summer sea ice variabilities depicted in Fig. 3 and the SAT and SLP patterns, the correlation coefficients between the PC1/PC2 and its associated SLP and SAT pattern index [defined by projecting the SLP and SAT regression pattern (Figs. 4a-d) upon the SLP and SAT anomaly field] are calculated in Table 7, following Deser et al. (2000). Nearly all 
TABLE 7. Correlation coefficients between summer Arctic sea ice PC1/PC2 and summer SLP pattern index and summer SAT pattern index. (The $95 \%$ significance levels in bold are determined by Student's $t$ test.)

\begin{tabular}{lcccccccc}
\hline \hline & \multicolumn{3}{c}{ SLP pattern index } & & \multicolumn{3}{c}{ SAT pattern index } \\
\cline { 2 - 5 } \cline { 7 - 8 } & $1850-$ & $1953-$ & $1979-$ & & $1850-$ & $1953-$ & $1979-$ \\
& 1952 & 2015 & 2015 & & 1952 & 2015 & 2015 \\
\hline PC1 & $\mathbf{0 . 2 0}$ & $\mathbf{0 . 3 3}$ & $\mathbf{0 . 4 2}$ & & $\mathbf{0 . 4 1}$ & $\mathbf{0 . 6 1}$ & $\mathbf{0 . 6 9}$ \\
PC2 & 0.17 & $\mathbf{0 . 4 2}$ & $\mathbf{0 . 3 5}$ & & $\mathbf{0 . 3 7}$ & $\mathbf{0 . 5 3}$ & $\mathbf{0 . 6 7}$ \\
\hline
\end{tabular}

of these temporal correspondences are statistically significant, especially for the PC1 and SAT pattern index (0.61 and 0.69 during 1953-2015 and 1979-2015, respectively), indicating the key role of Arctic warming in the accelerated Arctic sea ice loss. Olonscheck et al. (2019) pointed out that three-quarters of Arctic sea ice variability is directly caused by atmospheric temperature fluctuations and the advected atmospheric temperature fluctuations are the primary driver of sea ice variability. In this analysis, we demonstrate thermodynamic effect from AO, DA, NAO, AMO, and PDO, and the increasing influence on the amplified Arctic warming and sea ice loss.

One assumption of multiple linear regression is that all the climatology indices are not multicollinear. However, the climate system is nonlinear and chaotic. Zhang and Delworth (2007) found that the AMO can contribute to PDO and the associated Pacific-North America (PNA) pattern at the multidecadal time scale. Observational and modeling studies suggest that multidecadal variabilities of the atmospheric NAO are modulated by the AMO and PDO (Gastineau and Frankignoul 2012; Hodson et al. 2014; Yu et al. 2019). Furthermore, the contributions of external forcings could not be expressed explicitly in the regression models. This complicates the results of multiple linear regression. Thus, it is important to keep in mind that it is not possible to disentangle the complex interactions and strong coupling among the modes of the climate variability, especially under the anthropogenic warming. To separate the external forcings (e.g., anthropogenic aerosol and greenhouse gases) from internal climate variability and to quantify the relevance of each mode of the climate variability that causes interannual and decadal variability in sea ice is a challenging task when using statistical methods alone. An understanding of the causal relationship requires dynamic modeling with different scenarios, which is beyond the scope of the current study.

This analysis suggests a possible linkage to interannual and decadal time scale forcing via atmospheric teleconnections. Of course, we know that in addition to the changes of atmospheric circulation patterns, in the climate system, there is always more than one process occurring at the same time. These processes include, but are not limited to, increases of anthropogenic greenhouse gases and aerosols (Jahn 2018; Gagné et al. 2017; Halloran et al. 2020), changes in external natural forcing (Gagné et al. 2017; Haustein et al. 2019), moist and warm air intrusions into the Arctic (Woods and Caballero 2016), extratropical cyclones injecting air masses into the Arctic upper troposphere leading to Arctic anticyclones (Wernli and Papritz 2018), ocean heat transport into the Arctic (van der Linden et al. 2019), and so on. The changes of dominant modes of the internal climate variabilities and associated atmospheric circulations that are, presumably, mostly internally generated, are just one set of processes in the climate system that can contribute, along with other factors, to the trends in Arctic sea ice.

Acknowledgments. Q.C. thanks the National Natural Science Foundation of China (41606032 and 42176030) for supporting the research. J.W. appreciates support from NOAA GOMO/ CPO Arctic Research Program. This is NOAA GLERL contribution number 1990 and CIGLR contribution number 1184. R.L. is funded by the National Natural Science Foundation of China (41722605). We greatly appreciate three anonymous, enthusiastic reviewers for providing constructive suggestions and the editor Dr. J. Screen for suggesting the multiple regression analysis to significantly improve this study. We appreciate Ms. Nicole Rice of NOAA GLERL for editing this article.

Data availability statement. All data used in analysis are available in public repositories. The sea ice concentration data are downloaded from http://nsidc.org/data/g10010, http:// nsidc.org/data/G02202, and http://nsidc.org/data/G10016. The sea ice thickness (SIT) and motion data are from http:// psc.apl.uw.edu/research/projects/piomas-20c/. For the two twentieth-century reanalyses, 20CRv3 data are from https:// psl.noaa.gov/data/gridded/data.20thC_ReanV3.html, and ERA20C data are from https://www.ecmwf.int/en/forecasts/datasets/ reanalysis-datasets/era-20c. The NAO index is from https:// climatedataguide.ucar.edu/sites/default/files/nao_station_ monthly.txt. The HadISST1.1 used to calculate the AMO index is from https://www.metoffice.gov.uk/hadobs/ hadisst/data/download.html. The PDO is from http:// research.jisao.washington.edu/data_sets/pdo/. The multiple large ensembles of climate simulations (LEs) and single-forcing ensembles are downloaded from https://www.earthsystemgrid.org/ dataset/ucar.cgd.ccsm4.CLIVAR_LE.html and https:// www.cesm.ucar.edu/working_groups/CVC/simulations/ cesm1-single_forcing_le.html.

\section{REFERENCES}

Aagaard, K., and E. C. Carmack, 1994: The Arctic Ocean and climate: A perspective. The Polar Oceans and Their Role in Shaping the Global Environment: The Nansen Centennial Volume, Geophys. Monogr., Vol. 85, Amer. Geophys. Union, 5-20.

Alexander, M., U. Bhatt, J. Walsh, M. Timlin, J. Miller, and J. Scott, 2004: The atmospheric response to realistic Arctic sea ice anomalies in an AGCM during winter. J. Climate, 17, 890-905, https:// doi.org/10.1175/1520-0442(2004)017<0890:TARTRA > 2.0.CO;2.

Bonan, D., and E. Blanchard-Wrigglesworth, 2020: Nonstationary teleconnection between the Pacific Ocean and Arctic sea ice. Geophys. Res. Lett., 47, e2019GL085666, https://doi.org/10.1029/ 2019GL085666.

Bourke, R. H., and R. P. Garrett, 1987: Sea ice thickness distribution in the Arctic Ocean. Cold Reg. Sci. Technol., 13, 259280, https://doi.org/10.1016/0165-232X(87)90007-3. 
Brennan, M. K., G. J. Hakim, and E. Blanchard-Wrigglesworth, 2020: Arctic sea-ice variability during the instrumental era. Geophys. Res. Lett., 47, e2019GL086843, https://doi.org/ 10.1029/2019GL086843.

Cai, Q., J. Wang, D. Beletsky, J. E. Overland, M. Ikeda, and L. Wan, 2021: Accelerated decline of summer Arctic sea ice during 1850-2017 and the amplified Arctic warming during the recent decades. Environ. Res. Lett., 16, 034015, https://doi.org/ 10.1088/1748-9326/abdb5f.

Callendar, G. S., 1961: Temperature fluctuations and trends over the earth. Quart. J. Roy. Meteor. Soc., 87 (371), 1-12, https:// doi.org/10.1002/qj.49708737102.

Castruccio, F. S., Y. Ruprich-Robert, S. G. Yeager, G. Danabasoglu, R. Msadek, and T. L. Delworth, 2019: Modulation of Arctic sea ice loss by atmospheric teleconnections from Atlantic multidecadal variability. J. Climate, 32, 1419-1441, https://doi.org/ 10.1175/JCLI-D-18-0307.1.

Chylek, P., C. K. Folland, G. Lesins, M. K. Dubey, and M. Wang, 2009: Arctic air temperature change amplification and the Atlantic multidecadal oscillation. Geophys. Res. Lett., 36, L14801, https://doi.org/10.1029/2009GL038777.

Day, J. J., J. C. Hargreaves, J. D. Annan, and A. Abe-Ouchi, 2012: Sources of multi-decadal variability in Arctic sea ice extent. Environ. Res. Lett., 7, 034011, https://doi.org/10.1088/17489326/7/3/034011.

Deser, C., J. E. Walsh, and M. S. Timlin, 2000: Arctic sea ice variability in the context of recent atmospheric circulation trends. J. Climate, 13, 617-633, https://doi.org/10.1175/1520-0442(2000) 013<0617:ASIVIT>2.0.CO;2.

- R. A. Tomas, and L. Sun, 2015: The role of oceanatmosphere coupling in the zonal-mean atmospheric response to Arctic sea ice loss. J. Climate, 28, 2168-2186, https:// doi.org/10.1175/JCLI-D-14-00325.1.

— initial-condition large ensembles and future prospects. Nat. Climate Change, 10, 277-286, https://doi.org/10.1038/s41558020-0731-2.

—, A. Phillips, I. Simpson, N. Rosenbloom, D. Coleman, F. Lehner, and A. Pen-dergrass, 2020b: Isolating the evolving contributions of anthropogenic aerosols and greenhouse gases: A new CESM1 large ensemble community resource. J. Climate, 33, 7835-7858, https://doi.org/10.1175/JCLI-D-20-0123.1.

Ding, Q., and Coauthors, 2017: Influence of high-latitude atmospheric circulation changes on summertime Arctic sea ice. Nat. Climate Change, 7, 289-295, https://doi.org/10.1038/nclimate3241.

—_, and Coauthors, 2019: Fingerprints of internal drivers of Arctic sea ice loss in observations and model simulations. Nat. Geosci., 12, 28-33, https://doi.org/10.1038/s41561-018-0256-8.

England, M. R., 2021: Are multi-decadal fluctuations in Arctic and Antarctic surface temperatures a forced response to anthropogenic emissions or part of internal climate variability? Geophys. Res. Lett., 48, e2020GL090631, https:// doi.org/10.1029/2020GL090631.

_ A. Aahn, and L. Polvani, 2019: Non-uniform contribution of internal variability to recent Arctic sea ice loss. J. Climate, 32, 4039-4053, https://doi.org/10.1175/JCLI-D-18-0864.1.

— L. M. Polvani, L. Sun, and C. Deser, 2020: Tropical climate responses to projected Arctic and Antarctic sea-ice loss. Nat. Geosci., 13, 275-281, https://doi.org/10.1038/s41561020-0546-9.

Freund, J. E., and G. A. Simon, 1992: Modern Elementary Statistics. 8th ed. Prentice Hall, 321-323.

Gagné, M. È., J. C. Fyfe, N. P. Gillett, I. V. Polyakov, and G. M. Flato, 2017: Aerosol-driven increase in Arctic sea ice over the middle of the twentieth century. Geophys. Res. Lett., 44, 73387346, https://doi.org/10.1002/2016GL071941.

Gastineau, G., and C. Frankignoul, 2012: Cold-season atmospheric response to the natural variability of the Atlantic meridional overturning circulation. Climate Dyn., 39, 37-57, https:// doi.org/10.1007/s00382-011-1109-y.

Halloran, P. R., and Coauthors, 2020: Natural drivers of multidecadal Arctic sea ice variability over the last millennium. Sci. Rep., 10, 688, https://doi.org/10.1038/s41598-020-57472-2.

Haustein, K., and Coauthors, 2019: A limited role for unforced internal variability in twentieth-century warming. J. Climate, 32, 4893-4917, https://doi.org/10.1175/JCLI-D-18-0555.1.

Hegerl, G. C., S. Brönnimann, A. Schurer, and T. Cowan, 2018: The early 20th century warming: Anomalies, causes, and consequences. Wiley Interdiscip. Rev.: Climate Change, 9, e522, https://doi.org/10.1002/wcc.522.

Hodson, D. L. R., J. I. Robson, and R. T. Sutton, 2014: An anatomy of the cooling of the North Atlantic Ocean in the 1960s and 1970s. J. Climate, 27, 8229-8243, https://doi.org/10.1175/JCLID-14-00301.1.

Holland, M. M., C. M. Bitz, and A. J. Weaver, 2001: The influence of sea ice physics on simulations of climate change. J. Geophys. Res., 106, 19639-19655, https://doi.org/10.1029/ 2000JC000651.

Hurrell, J. W., 1995: Decadal trends in the North Atlantic Oscillation: Regional temperatures and precipitation. Science, 269, 676-679, https://doi.org/10.1126/science.269.5224.676.

Ikeda, M., 2012: Sea-ice cover anomalies in the Arctic Basin associated with the atmospheric variability from multi-decadal trend to intermittent quasi-biennial oscillations. Polar Res., 31, 18690, https://doi.org/10.3402/polar.v31i0.18690.

_ J. Wang, and J.-P. Zhao, 2001: Hypersensitive decadal oscillations in the Arctic/subarctic climate. Geophys. Res. Lett., 28, 1275-1278, https://doi.org/10.1029/2000GL011773.

Jahn, A., 2018: Reduced probability of ice-free summers for $1.5^{\circ} \mathrm{C}$ compared to $2^{\circ} \mathrm{C}$ warming. Nat. Climate Change, 8, 409-413, https://doi.org/10.1038/s41558-018-0127-8.

Jeffrey, S., and Coauthors, 2013: Australia's CMIP5 submission using the CSIRO-Mk3.6 model. Aust. Meteor. Oceanogr. J., 63 (1), 1-13, https://doi.org/10.22499/2.6301.001.

Kay, J., and Coauthors, 2015: The Community Earth System Model (CESM) large ensemble project: A community resource for studying climate change in the presence of internal climate variability. Bull. Amer. Meteor. Soc., 96, 1333-1349, https:// doi.org/10.1175/BAMS-D-13-00255.1.

Kim, J.-H., and Coauthors, 2019: Reconstructing spring sea ice concentration in the Chukchi Sea over recent centuries: Insights into the application of the PIP25 index. Environ. Res. Lett., 14, 125004, https://doi.org/10.1088/1748-9326/ab4b6e.

Kinnard, C., C. M. Zdanowicz, D. A. Fisher, E. Isaksson, A. de Vernal, and L. G. Thompson, 2011: Reconstructed changes in Arctic sea ice over the past 1450 years. Nature, 479, 509-512, https://doi.org/10.1038/nature10581.

Kirchmeier-Young, M., F. Zwiers, and N. Gillett, 2017: Attribution of extreme events in Arctic sea ice extent. J. Climate, 30, 553571, https://doi.org/10.1175/JCLI-D-16-0412.1.

Klaus, D., P. Wyszyński, K. Dethloff, R. Przybylak, and A. Rinke, 2018: Evaluation of 20CR reanalysis data and model results based on historical (1930-1940) observations from Franz Josef Land. Pol. Polar Res., 39, 225-254, https:// doi.org/10.24425/118747.

Koenigk, T., U. Mikolajewicz, J. H. Jungclaus, and A. Kroll, 2009: Sea ice in the Barents Sea: Seasonal to interannual variability 
and climate feedbacks in a global coupled model. Climate Dyn., 32, 1119-1138, https://doi.org/10.1007/s00382-008-0450-2.

Kolstad, E. W., and J. A. Screen, 2019: Nonstationary relationship between autumn Arctic sea ice and the winter North Atlantic Oscillation. Geophys. Res. Lett., 46, 7583-7591, https://doi.org/ 10.1029/2019GL083059.

Lei, R., X. Tian-Kunze, M. Lepparanta, J. Wang, L. Kaleschke, and Z. Zhang, 2016: Changes in summer sea ice, albedo, and portioning of surface solar radiation in the Pacific sector of Arctic Ocean during 1982-2009. J. Geophys. Res. Oceans, 121, 5470-5486, https://doi.org/10.1002/2016JC011831.

_- B. Cheng, P. Heil, T. Vihma, J. Wang, Q. Ji, and Z. Zhang, 2018: Seasonal and interannual variabilities of sea ice mass balance from the Central Arctic to the Greenland Sea. J. Geophys. Res. Oceans, 123, 2422-2439, https://doi.org/10.1002/2017JC013548.

Levitus, S., G. Matishov, D. Seidov, and I. Smolyar, 2009: Barents Sea multidecadal variability. Geophys. Res. Lett., 36, L19604, https://doi.org/10.1029/2009GL039847.

Li, Y., D. W. J. Thompson, Y. Huang, and M. Zhang, 2014: Observed linkages between the northern annular mode/North Atlantic Oscillation, cloud incidence, and cloud radiative forcing. Geophys. Res. Lett., 41, 1681-1688, https://doi.org/ 10.1002/2013GL059113.

Mantua, N. J., S. R. Hare, Y. Zhang, J. M. Wallace, and R. C. Francis, 1997: A Pacific interdecadal climate oscillation with impacts on salmon production. Bull. Amer. Meteor. Soc., 78, 1069-1079, https://doi.org/10.1175/1520-0477(1997)078<1069: APICOW $>2.0 . C O ; 2$.

McCrystall, M. R., J. S. Hosking, I. P. White, and A. C. Maycock, 2020: The impact of changes in tropical sea surface temperatures over 1979-2012 on Northern Hemisphere high-latitude climate. J. Climate, 33, 5103-5121, https://doi.org/10.1175/ JCLI-D-19-0456.1.

Meehl, G. A., C. T. Chung, J. M. Arblaster, M. M. Holland, and C. M. Bitz, 2018: Tropical decadal variability and the rate of Arctic sea ice decrease. Geophys. Res. Lett., 45, 11 326-11333, https://doi.org/10.1029/2018GL079989.

Meier, W., F. Fetterer, and A. K. Windnagel, 2017: Near-Real-Time NOAA/NSIDC Climate Data Record of Passive Microwave Sea Ice Concentration, version 1. NSIDC, accessed 2018, https:// doi.org/10.7265/N5FF3QJ6.

—_, and Coauthors, 2020: 2020 sea ice outlook interim post-season report. https://www.arcus.org/sipn/sea-ice-outlook/2020/interim.

Min, S.-K., X. Zhang, F. W. Zwiers, and T. Agnew, 2008: Human influence on Arctic sea ice detectable from early 1990s onwards. Geophys. Res. Lett., 35, L21701, https://doi.org/10.1029/ 2008 GL035725.

Moore, G. W. K., A. Schweiger, J. Zhang, and M. Steele, 2019: Spatiotemporal variability of sea ice in the Arctic's last ice area. Geophys. Res. Lett., 46, 11 237-11243, https://doi.org/ 10.1029/2019GL083722.

Ogi, M., and J. M. Wallace, 2007: Summer minimum Arctic sea ice extent and the associated summer atmospheric circulation. Geophys. Res. Lett., 34, L12705, https://doi.org/10.1029/2007GL029897.

Olonscheck, D., T. Mauritsen, and D. Notz, 2019: Arctic sea-ice variability is primarily driven by atmospheric temperature fluctuations. Nat. Geosci., 12, 430-434, https://doi.org/10.1038/s41561-019-0363-1.

Overland, J. E., and M. Wang, 2005: The third Arctic climate pattern: 1930s and early 2000s. Geophys. Res. Lett., 32, L23808, https://doi.org/10.1029/2005GL024254.

_, K. R. Wood, and M. Wang, 2011: Warm Arctic-cold continents: Climate impacts of the newly open Arctic sea. Polar Res., 30, 15787, https://doi.org/10.3402/polar.v30i0.15787.
Papritz, L., 2020: Arctic lower-tropospheric warm and cold extremes: Horizontal and vertical transport, diabatic processes, and linkage to synoptic circulation features. J. Climate, $\mathbf{3 3}$, 993-1016, https://doi.org/10.1175/JCLI-D-19-0638.1.

Parkinson, C. L., and D. J. Cavalieri, 1989: Arctic sea ice 19731987: Seasonal, regional, and interannual variability. J. Geophys. Res., 94, 14 499-14523, https://doi.org/10.1029/ JC094iC10p14499.

— , and J. C. Comiso, 2013: On the 2012 record low Arctic sea ice cover: Combined impact of preconditioning and an August storm. Geophys. Res. Lett., 40, 1356-1361, https://doi.org/ $10.1002 /$ grl.50349.

Peng, G., W. Meier, D. Scott, and M. Savoie, 2013: A long-term and reproducible passive microwave sea ice concentration data record for climate studies and monitoring. Earth Syst. Sci. Data, 5, 311-318, https://doi.org/10.5194/essd-5-3112013.

Peralta-Ferriz, C., and R. A. Woodgate, 2017: The dominant role of the east Siberian Sea in driving the oceanic flow through the Bering Strait-Conclusions from GRACE Ocean mass satellite data and in situ mooring observations between 2002 and 2016. Geophys. Res. Lett., 44, 11-472, https://doi.org/10.1002/ 2017 GL075179.

Poli, P., and Coauthors, 2016: ERA-20C: An atmospheric reanalysis of the twentieth century. J. Climate, 29, 4083-4097, https://doi.org/10.1175/JCLI-D-15-0556.1.

Randall, D., and Coauthors, 1998: Status of and outlook for largescale modeling of atmosphere-ice-ocean interactions in the Arctic. Bull. Amer. Meteor. Soc., 79, 197-219, https://doi.org/ 10.1175/1520-0477(1998)079<0197:SOAOFL>2.0.CO;2.

Rigor, I. G., J. M. Wallace, and R. L. Colony, 2002: Response of sea ice to the Arctic Oscillation. J. Climate, 15, 2648-2663, https://doi.org/10.1175/1520-0442(2002)015<2648:ROSITT> 2.0.CO;2.

Rodgers, K., J. Lin, and T. Frolicher, 2015: Emergence of multiple ocean ecosystem drivers in a large ensemble suite with an Earth system model. Biogeosciences, 12, 3301-3320, https:// doi.org/10.5194/bg-12-3301-2015.

Schlesinger, M. E., and N. Ramankutty, 1994: An oscillation in the global climate system of period 65-70 years. Nature, 367, 723726, https://doi.org/10.1038/367723a0.

Schneider, D. P., C. Deser, J. Fasullo, and K. E. Trenberth, 2013: Climate data guide spurs discovery and understanding. Eos, Trans. Amer. Geophys. Union, 94, 121-122, https://doi.org/ 10.1002/2013EO130001.

Schweiger, A., R. Lindsay, J. Zhang, M. Steele, H. Stern, and R. Kwok, 2011: Uncertainty in modeled Arctic sea ice volume. J. Geophys. Res., 116, C00D06, https://doi.org/10.1029/ 2011JC007084.

— , K. R. Wood, and J. Zhang, 2019: Arctic sea ice volume variability over 1901-2010: A model-based reconstruction. J. Climate, 32, 4731-4752, https://doi.org/10.1175/JCLI-D-190008.1.

Screen, J. A., and J. A. Francis, 2016: Contribution of sea-ice loss to Arctic amplification is regulated by Pacific Ocean decadal variability. Nat. Climate Change, 6, 856-860, https://doi.org/ 10.1038/nclimate3011.

, and C. Deser, 2019: Pacific Ocean variability influences the time of emergence of a seasonally ice-free Arctic Ocean. Geophys. Res. Lett., 46, 2222-2231, https://doi.org/10.1029/ 2018GL081393.

— , and Coauthors, 2018: Consistency and discrepancy in the atmospheric response to Arctic sea-ice loss across climate 
models. Nat. Geosci., 11, 155-163, https://doi.org/10.1038/ s41561-018-0059-y.

Sedlar, J., and M. Tjernström, 2017: Clouds, warm air, and a climate cooling signal over the summer Arctic. Geophys. Res. Lett., 44, 1095-1103, https://doi.org/10.1002/2016GL071959.

Serreze, M. C., and R. G. Barry, 2011: Processes and impacts of Arctic amplification: A research synthesis. Global Planet. Change, 77, 85-96, https://doi.org/10.1016/j.gloplacha.2011.03.004.

— cations for seasonal ice forecasting. Philos. Trans. Roy. Soc., 373A, 20140159, https://doi.org/10.1098/rsta.2014.0159.

- - A. P. Barrett, A. D. Crawford, and R. A. Woodgate, 2019: Monthly variability in Bering Strait oceanic volume and heat transports, links to atmospheric circulation and ocean temperature, and implications for sea ice conditions. J. Geophys. Res. Oceans, 124, 9317-9337, https:// doi.org/10.1029/2019JC015422.

Skeie, P., 2000: Meridional flow variability over the Nordic seas in the Arctic Oscillation framework. Geophys. Res. Lett., 27, 2569-2572, https://doi.org/10.1029/2000GL011529.

Slivinski, L. C., and Coauthors, 2019: Towards a more reliable historical reanalysis: Improvements for version 3 of the Twentieth Century Reanalysis system. Quart. J. Roy. Meteor. Soc., 145, 2876-2908, https://doi.org/10.1002/qj.3598.

Spreen, G., R. Kwok, and D. Menemenlis, 2011: Trends in Arctic sea ice drift and role of wind forcing: 1992-2009. Geophys. Res. Lett., 38, L19501, https://doi.org/10.1029/2011GL048970.

Stroeve, J., M. M. Holland, W. Meier, T. Scambos, and M. Serreze, 2007: Arctic sea ice decline: Faster than forecast. Geophys. Res. Lett., 34, L09501, https://doi.org/10.1029/2007GL029703.

Strong, C., and G. Magnusdottir, 2010: Modeled winter sea ice variability and the North Atlantic Oscillation: A multi-century perspective. Climate Dyn., 34, 515-525, https://doi.org/10.1007/ s00382-009-0550-7.

—_, and I. G. Rigor, 2013: Arctic marginal ice zone trending wider in summer and narrower in winter. Geophys. Res. Lett., 40, 4864-4868, https://doi.org/10.1002/grl.50928.

-_, G. Magnusdottir, and H. Stern, 2009: Observed feedback between winter sea ice and the North Atlantic Oscillation. J. Climate, 22, 6021-6032, https://doi.org/ 10.1175/2009JCLI3100.1.

Sun, L., M. Alexander, and C. Deser, 2018: Evolution of the global coupled climate response to Arctic sea ice loss during 19902090 and its contribution to climate change. J. Climate, 31, 7823-7843, https://doi.org/10.1175/JCLI-D-18-0134.1.

Svendsen, L., N. Keenlyside, I. Bethhke, Y. Gao, and N.-E. Omrani, 2018: Pacific contribution to the early twentiethcentury warming in the Arctic. Nat. Climate Change, 8, 793797, https://doi.org/10.1038/s41558-018-0247-1.

Tokinaga, H., S.-P. Xie, and H. Mukougawa, 2017: Early 20thcentury Arctic warming intensified by Pacific and Atlantic multidecadal variability. Proc. Natl. Acad. Sci. USA, 114, 6227-6232, https://doi.org/10.1073/pnas.1615880114.

Trenberth, K. E., and D. J. Shea, 2006: Atlantic hurricanes and natural variability in 2005. Geophys. Res. Lett., 33, L12704, https://doi.org/10.1029/2006GL026894.

Trusel, L. D., and Coauthors, 2018: Nonlinear rise in Greenland runoff in response to post-industrial Arctic warming. Nature, 564, 104-108, https://doi.org/10.1038/s41586-018-0752-4.

van der Linden, E. C., D. Le Bars, R. Bintanja, and W. Hazeleger, 2019: Oceanic heat transport into the Arctic under high and low $\mathrm{CO}_{2}$ forcing. Climate Dyn., 53, 4763-4780, https://doi.org/ 10.1007/s00382-019-04824-y.
Walsh, J. E., 1983: Role of sea ice in climate variability: Theories and evidence. Atmos.-Ocean, 21, 229-242, https://doi.org/ 10.1080/07055900.1983.9649166.

—_, and C. M. Johnson, 1979: An analysis of Arctic sea ice fluctuations, 1953-77. J. Phys. Oceanogr., 9, 580-591, https://doi.org/10.1175/1520-0485(1979)009<0580:AAOASI > 2.0.CO;2.

—_, F. Fetterer, J. S. Stewart, and W. L. Chapman, 2017: A database for depicting Arctic sea ice variations back to 1850. Geogr. Rev., 107, 89-107, https://doi.org/10.1111/ j.1931-0846.2016.12195.x.

Wang, J., and M. Ikeda, 2000: Arctic Oscillation and Arctic sea-ice oscillation. Geophys. Res. Lett., 27, 1287-1290, https://doi.org/ 10.1029/1999GL002389.

$\longrightarrow$, and - 2001: Arctic sea-ice oscillation: Regional and seasonal perspectives. Ann. Glaciol., 33, 481-492, https://doi.org/ 10.3189/172756401781818626.

,$- \ldots$, S. Zhang, and R. Gerdes, 2005: Linking the Northern Hemisphere sea ice reduction trend and the quasi-decadal Arctic sea ice oscillation. Climate Dyn., 24, 115-130, https:// doi.org/10.1007/s00382-004-0454-5.

— J J. Zhang, E. Watanabe, M. Ikeda, K. Mizobata, J. E. Walsh, X. Bai, and B. Wu, 2009: Is the Dipole Anomaly a major driver to record lows in the Arctic summer sea ice extent? Geophys. Res. Lett., 36, L05706, https://doi.org/10.1029/ 2008 GL036706.

— ice-ocean processes in the Pacific Arctic region and the Bering Sea. The Pacific Arctic Region: Ecosystem Status and Trends in a Rapidly Changing Environment, J. M. Grebmeier and W. Maslowski, Eds., Springer, 65-100.

Watanabe, E., J. Wang, A. Sumi, and H. Hasumi, 2006: Arctic Dipole Anomaly and its contribution to sea ice export from the Arctic Ocean in the 20th century. Geophys. Res. Lett, 33, L23703, https://doi.org/10.1029/2006gl028112.

Wernli, H., and L. Papritz, 2018: Role of polar anticyclones and mid-latitude cyclones for Arctic summertime sea-ice melting. Nat. Geosci., 11, 108-113, https://doi.org/10.1038/s41561-0170041-0.

Wettstein, J. J., and C. Deser, 2014: Internal variability in projections of twenty-first century Arctic sea ice loss: Role of the large-scale atmospheric circulation. J. Climate, 27, 527-550, https://doi.org/10.1175/JCLI-D-12-00839.1.

Woods, C., and R. Caballero, 2016: The role of moist intrusions in winter Arctic warming and sea ice decline. J. Climate, 29, 4473-4485, https://doi.org/10.1175/JCLID-15-0773.1.

Wu, B., J. Wang, and J. E. Walsh, 2006: Dipole anomaly in the winter Arctic atmosphere and its association with Arctic sea ice motion. J. Climate, 19, 210-225, https://doi.org/10.1175/ JCLI3619.1.

Yu, L., S. Zhong, M. Zhou, D. H. Lenschow, and B. Sun, 2019: Revisiting the linkages between the variability of atmospheric circulations and Arctic melt-season sea ice cover at multiple time scales. J. Climate, 32, 1461-1482, https://doi.org/10.1175/ JCLI-D-18-0301.1.

Zhang, J., and D. A. Rothrock, 2003: Modeling global sea ice with a thickness and enthalpy distribution model in generalized curvilinear coordinates. Mon. Wea. Rev., 131, 845-861, https://doi.org/10.1175/1520-0493(2003) $131<0845$ :MGSIWA $>2.0 . \mathrm{CO} ; 2$.

- — - and M. Steele, 2000: Recent changes in Arctic sea ice: The interplay between ice dynamics and thermodynamics. 
J. Climate, 13, 3099-3114, https://doi.org/10.1175/15200442(2000)013<3099:RCIASI > 2.0.CO;2.

R. Lindsay, M. Steele, and A. Schweiger, 2008: What drove the dramatic retreat of Arctic sea ice during summer 2007? Geophys. Res. Lett., 35, L11505, https://doi.org/10.1029/ 2008 GL034005.

_, - _ A. Schweiger, and I. Rigor, 2012: Recent changes in the dynamic properties of declining Arctic sea ice: A model study. Geophys. Res. Lett., 39, L20503, https:// doi.org/10.1029/2012GL053545.
Zhang, R., 2015: Mechanisms for low-frequency variability of summer Arctic sea ice extent. Proc. Natl. Acad. Sci. USA, 112, 4570-4575, https://doi.org/10.1073/pnas.1422296112.

— decadal oscillation on North Pacific climate variability. Geophys. Res. Lett., 34, L23708, https://doi.org/10.1029/ 2007 GL031601.

Zhang, Y., J. M. Wallace, and D. S. Battisti, 1997: ENSO-like interdecadal variability: 1900-93. J. Climate, 10, 1004-1020, https:// doi.org/10.1175/1520-0442(1997)010<1004:ELIV>2.0.CO;2. 